\title{
Numerical Investigation of Residual Displacement of Rocking Self-Centering Columns Under Cyclic Loading
}

\section{Yan Shi}

Lanzhou University of Technology

zhengwu zhong ( zzw0730@163.com )

Lanzhou University of Technology https://orcid.org/0000-0002-3662-4320

Zhichao Zhang

Lanzhou University of Technology

Jianping Han

Lanzhou University of Technology

Hu Cheng

Jiangnan University

\section{Research Article}

Keywords: Rocking self-centering column, Residual displacement, Cyclic loading, Factorial analysis

Posted Date: July 16th, 2021

DOI: https://doi.org/10.21203/rs.3.rs-706183/v1

License: (c) (i) This work is licensed under a Creative Commons Attribution 4.0 International License. Read Full License 


\title{
Numerical investigation of residual displacement of rocking
} self-centering columns under cyclic loading

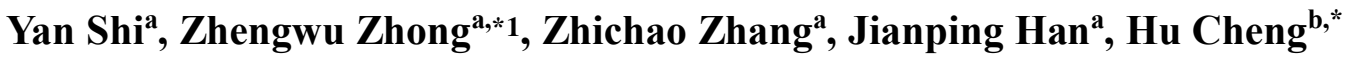

${ }^{a}$ School of Civil Engineering, Lanzhou University of Technology, Lanzhou 730050,

\section{China}

${ }^{b}$ School of Environment and Civil Engineering, Jiangnan University, Wuxi214122,

\section{China}

Corresponding author.

E-mail addresses: syky86@163.com(Y.Shi),zzw0730@163.com (Z.Zhong),Zhangzhic0303@163.com (Z. Zhang), jphan1970@163.com(J. Han), hcheng@jiangnan.edu.cn(C. Hu). 


\author{
Yan Shi ${ }^{\mathrm{a}}$, Zhengwu Zhong ${ }^{\mathrm{a}, *}$, Zhichao Zhang ${ }^{\mathrm{a}}$, Jianping Han, Hu Cheng ${ }^{\mathrm{b}, *}$ \\ ${ }^{a}$ School of Civil Engineering, Lanzhou University of Technology, Lanzhou 730050,
}

\section{China}

${ }^{b}$ School of Environment and Civil Engineering, Jiangnan University, Wuxi214122,

\section{China}

\section{Abstract}

4 Well-designed rocking self-centering (RSC) columns are capable of achieving small

5 residual displacement. However, few studies conducted the quantitative analysis for the

6 residual displacement of RSC columns. The residual displacement is the product of the

7 struggle between the self-centering (SC) capacity and the energy dissipation (ED)

8 capacity. In this study, a SC factor and an ED parameter were defined to reflect the SC

9 and ED capacity of the RSC column, respectively. The influence of eight common

10 design parameters on the SC factor and the ED parameter was explored using factorial analysis. Parametric analysis was performed to investigate the tendency of the SC factor and the ED parameter with the increase of maximum drift. According to the results of the parametric analysis, the effect of the SC factor and the ED parameter on the distribution of the residual drift was researched statistically. A simplified formula was proposed to calculate the upper limit of the residual drift. What is more, a set of predictive regression formulas was established to estimate the actual residual drift, these regression formulas have an applicable condition that the ED parameter should be larger 
than 0.75 . When the ED parameter was less than 0.75 , the residual drift is approximate to zero.

Keywords Rocking self-centering column - Residual displacement • Cyclic loading $•$ Factorial analysis

\section{Introduction}

Past devastating earthquakes have demonstrated that the reinforced concrete (RC) bridge structures are highly vulnerable to earthquakes with extensive damage concentrated in plastic region of bridge pier (Han et al. 2009; Shi et al. 2020). It is likely to cause large residual displacement as a result of serious damage. The bridge structure with significant permanent displacement is hard to return back to the initial position, which causes tremendous difficulties to the post-earthquake recovery and huge economic losses (Kawashima et al. 1998). For example, about $100 \mathrm{RC}$ bridge piers were eventually demolished due to a residual drift ratio of $1.75 \%$ after the 1995 Kobe earthquake in Japan (Kawashima et al. 1998). Therefore, the residual displacement is regarded as a main index to evaluate the earthquake resilience and the self-centering capacity of piers become an important design consideration (Uma et al. 2010; Palermo and Mashal. 2012).

Based on accelerated bridge construction philosophy, the rocking self-centering (RSC) column was proposed, and the post-tensioning has been considered to be an efficient way to drastically reduce the residual displacement (Marsh et al. 2011). To data, many experimental studies have been carried out to address the seismic behavior of RSC columns (Hewes and Priestley. 2002; Palermo et al. 2007; Ou et al. 2010; Bu et al. 
2016; Elgawady and Sha'lan. 2011; Guo et al. 2015; Han et al. 2019; Tong et al. 2019;

Cai et al. 2017; Roh and Reinhorn. 2010). Hewes and Priestley (2002) performed an early cyclic test of the RSC column, the result shown that the segments of the pier basically remained elastic and the residual drift was very small. However, the energy dissipation (ED) capacity was extremely weak due to the lack of ED elements. To enhance the ED capacity of RSC columns, various types of dissipaters were proposed and the ED bar is the commonest ED device among these dissipaters. The results of many cyclic tests shown that the hysteretic curve of the RSC column equipped with ED elements was much fuller, and the ED capacity was improved as expected (Palermo et al. 2007; Ou et al. 2010; Bu et al. 2016; Elgawady and Sha'lan. 2011; Guo et al. 2015; Han et al. 2019). Meanwhile, the added ED elements reduced the SC capacity of RSC columns, leading to the problem of residual displacement could not be ignored if too many dissipaters were used. Some researchers tried to use high performance materials (e.g. shape memory alloy, fiber-reinforced polymer composite bar) to achieve a balance between SC and ED capacity (Tong et al. 2019; Cai et al. 2017; Roh and Reinhorn. 2010). It can be concluded that there is a trade-off between the SC and ED capacity, the residual displacement is the product of their mutual struggle.

The harm of residual displacement has been realized gradually, and residual displacement has been regarded as an important consideration in seismic design. According to earthquake damage investigation results, the Japan Road Association code first proposed a reparability limit of $1 \%$ for RC columns (Japan Road Association, 2002). Some researches focusing on the residual displacement of RC columns have 
been conducted, aiming to explore the influence factors and achieve the estimation of residual displacement under earthquakes. It can be concluded that the residual drift is determined by structural properties and characteristics of earthquake load both (Liossatou and Fardis. 2016; Cheng et al. 2016; Liossatou and Fardis. 2015; Ji et al. 2018; Amiri and Bojorquez. 2019; Zhan and Jian. 2018; Quinde et al. 2019). However, few studies related to the residual displacement estimation of RSC columns have been reported. Li et al. (2020) selected residual drift as a performance index to conduct seismic vulnerability analysis and losses assessment of an RSC bridge system. Ou et al. (2007) developed a three-dimensional model of the RSC column equipped with internal ED bars, the results of cyclic loading analyses suggested an optimum ED bar ratio of $0.5 \%$ around. Cai et al. (2019) performed cyclic analyses to investigate the influence of post-tensioning force, gravity load, ED bar ratio and aspect ratio on the residual drift of RSC columns. Liu et al (2018) carried out parametric analyses on residual displacement under cyclic loading. Wang et al. (2019) proposed a simplified formula for UHPC bridge columns with unbonded post-tensioning tendons to calculate the upper limit of residual drift under cyclic loading. In conclusion, the residual drift of RSC columns under cyclic loading mainly depends on structural properties, quantitative analysis of residual drift is still limited in previous work.

The purpose of this study is exploring the distribution of residual drift of RSC columns under cyclic loading and achieving its prediction. Two governing parameters including a SC factor and an ED parameter were introduced to describe the SC capacity and ED capacity of piers. The contribution of eight common design parameters to the 
84

SC factor and ED parameter was compared. Then the effect of the SC factor and ED parameter on the residual drift was investigated, a set of predictive formulas for the residual drift was obtained from regressive analyses and an application of it was given.

\section{Simulation of RSC columns}

\subsection{Simulation method}

To capture the hysteretic behavior of the RSC columns, a numerical model is established using OpenSees. Fig. 1 shows the schematic of the analytical model. The displacement of the RSC columns is dominated by rigid rotation, the bending deformation occurs before the column lifts up and its contribution is very small, so the elastic beam-column elements can be used to model the column, this simplified simulation strategy was also adopted in previous studies (Ahmdi and Kashani, 2020; Marriott et al. 2009). A lumped mass is applied at the pier top to represent the gravity load, and a horizontal constraint is set at the bottom to prevent the relative slide between the column and the foundation. CorotTruss elements composed of elastic-perfectly-plastic material are considered to model the force-displacement of the unbonded post-tensioning (PT) tendons. The bottom nodes of the tendons are fixed, and the top nodes are connected with the corresponding column node with rigid links. A similar simulation method is adopted to model the unbonded segments of the energy dissipation (ED) bars. Truss elements with Reinforcing Steel material are used to model the ED bars, and the ultimate stress is set to 1.35 times as much as the yield stress $f_{\mathrm{y}}$ (Priestley et al. 2007); the ratio of the tangent at initial strain hardening to the initial elastic tangent can be set to $0.01-0.05$ (Cai et al. 2019) (0.03 is selected in this study), 

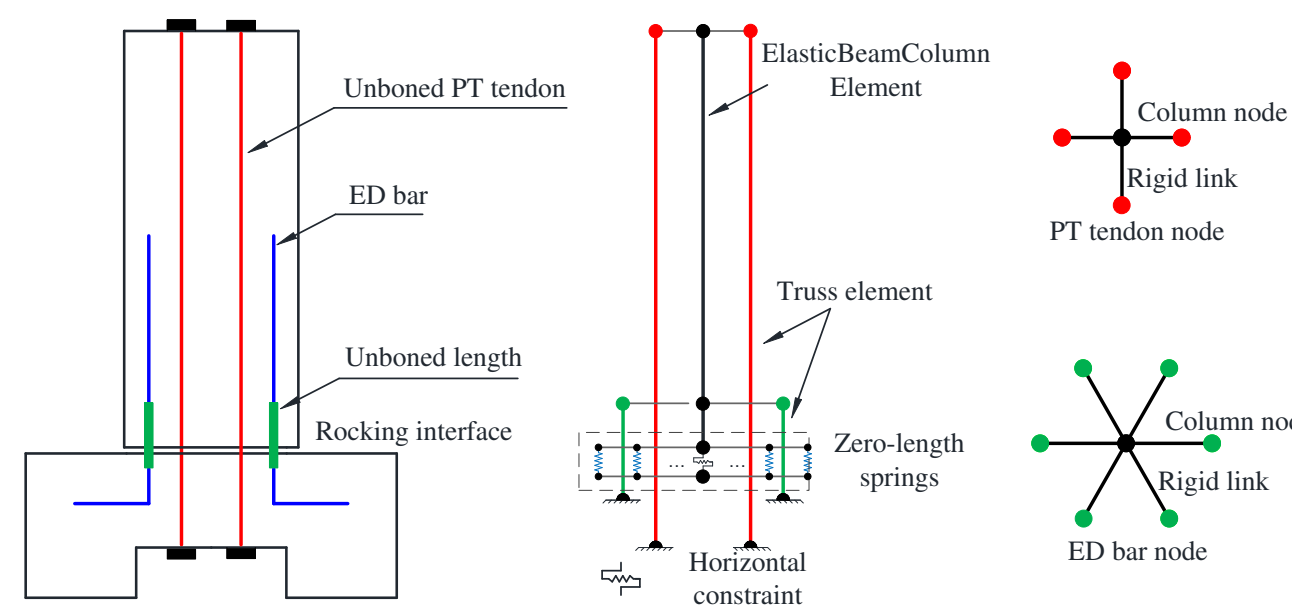

Fig. 1 Finite element model and cross-sections of existed test specimens

ED bars, the other is the equivalent unbonded length $\left(L_{\mathrm{eu}}\right)$ caused by the strain penetration. The $L_{\mathrm{ub}}$ can be expressed as:

$$
L_{\mathrm{ub}}=L_{0}+L_{\mathrm{eu}}
$$

lateral displacement. As a result, the strength of an RSC column will be overestimated.

The value of $L_{\mathrm{eu}}$ is significant, but it is difficult to determine its value precisely because of the complexity of the strain penetration. For example, Mantawy et al. (2019) suggested to adopt an iterative method to determine the value of $L_{\mathrm{ub}}$, the trial value of $L_{\mathrm{ub}}$ continued to increase until the correct bridge stiffness was calibrated. 
method for RSC columns (Pampanin et al. 2001; Bu and Ou, 2013). According to the monolithic beam analogy, the stress of ED bars can be expressed as follows (Pampanin et al. 2001):

$$
\varepsilon_{\mathrm{s}}=\frac{\left[\left(\Delta+2 / 3 l_{\mathrm{sp}} \alpha \varepsilon_{\mathrm{y}}\right)\right]}{\left(L_{0}+2 l_{\mathrm{sp}}\right)} \approx \frac{\Delta}{\left(L_{0}+2 l_{\mathrm{sp}}\right)}
$$

where $\Delta$ is elongation of an ED bar, due to the opening of the joint; $\varepsilon_{\mathrm{y}}$ is yield strain of ED bars; $\alpha$ is ratio of elastic strain and yield strain in reinforcement; $l_{\mathrm{sp}}$ is strain penetration taken as $0.022 f_{\mathrm{y}} d_{\mathrm{b}}, f_{\mathrm{y}}$ and $d_{\mathrm{b}}$ are the yield stress and diameter of ED bars, respectively. All units in MPa and mm. From Eq. (2), $L_{\mathrm{eu}}$ can be calculated as:

$$
L_{\mathrm{eu}}=2 l_{\mathrm{sp}}=2 \times 0.022 f_{\mathrm{y}} d_{\mathrm{b}}
$$

In Bu's study, $L_{\text {eu }}$ is calculated with Eq. (4) (Bu and Ou, 2013).

$$
L_{\mathrm{eu}}=\left\{\begin{array}{cc}
0 & , f_{s}>f_{y} \\
\frac{2.1 \times\left(f_{s}-f_{y}\right)}{\left(f_{g}\right)^{1.5}} d_{\mathrm{b}}, f_{s}>f_{y}
\end{array}\right.
$$

where $f_{\mathrm{s}}$ is stress of ED bars; $f_{\mathrm{g}}$ is compression strength of grout.

By trial calculation, it can be found that the calculated results obtained from Eq. (3) are much larger than the results of Eq. (4) generally. Therefore, Eq. (3) is used to determine the maximum value of $L_{\mathrm{ub}}$. Though the precise value of $L_{\mathrm{ub}}$ is hard to determine, the range of $L_{\mathrm{ub}}$ can be estimated by Eq. (5), in the later analysis, the influence of $L_{\mathrm{ub}}$ on residual displacement will be discussed.

$$
\operatorname{Min} L_{\mathrm{ub}}=L_{\mathrm{0}}<L_{\mathrm{ub}}<L_{0}+2 \times 0.022 f_{\mathrm{y}} d_{\mathrm{b}}=\operatorname{Max} L_{\mathrm{ub}}
$$

Several compression-only springs are used to model the opening and closing of the bottom rocking interface. Generally, the simulation result will become stable gradually 
as the number of springs increases. These springs are distributed in a uniform way, the distance between two adjacent springs is equal and all springs have the same axial stiffness. The axial stiffness, $k$, can be calculated as (Li et al, 2020):

$$
k=\frac{2 E_{c} A_{g}}{n H}
$$

where $E_{c}=4700 \sqrt{f_{c}^{\prime}}$ is the elastic modulus of the concrete, $f_{c}^{\prime}$ is the concrete compressive strength (Ahmdi and Kashani, 2020); $A_{\mathrm{g}}$ is the gross area of the column section; $H$ is the column height; $n$ is the number of zero-length springs.

\subsection{Model validation}

Table 1 Properties of selected specimen

\begin{tabular}{ccccc}
\hline Specimen & PT1 & HBD2 & HBD1 & s-SCP(I-ED) \\
\hline Geometry & $350 \times 350 \mathrm{~mm}$ & $350 \times 350 \mathrm{~mm}$ & $350 \times 350 \mathrm{~mm}$ & $400 \times 400 \mathrm{~mm}$ \\
Aspect ratio & 4.57 & 4.57 & 4.57 & 3.78 \\
Total axial load & $200 \mathrm{kN}$ & $300 \mathrm{k}$ & $200 \mathrm{kN}$ & $533.05 \mathrm{kN}$ \\
Tendons & $2 \times 99 \mathrm{~mm} 2$ & $4 \times 99 \mathrm{~mm} 2$ & $2 \times 99 \mathrm{~mm} 2$ & $4 \Phi 15.2$ \\
& $100 \mathrm{kN}$ each & $75 \mathrm{kN}$ each & $100 \mathrm{kN}$ each & $313.05 \mathrm{kN}$ total \\
& & $4-\mathrm{HD} 20$ & $4-\mathrm{D} 16$ & $4-\mathrm{D} 20$ \\
Dissipation & None & $12.5 \mathrm{~mm}$ diameter fuse & reinforcing steel & reinforcing steel \\
& & $50 \mathrm{~mm}$ fuse length & $L_{0}=50 \mathrm{~mm}$ & $L_{0}=100 \mathrm{~mm}$ \\
& & $f_{\mathrm{y}=586 \mathrm{MPa}}$ & $f_{\mathrm{y}=304 \mathrm{MPa}}$ & $f_{\mathrm{y}}=349 \mathrm{MPa}$ \\
\hline
\end{tabular}

In order to validate the simulation method, 4 RSC bridge pier specimens are selected (Palermo et al. 2007; Guo et al, 2012), as reported in Table 1. PT1 has no dissipation elements, it can be used to confirm the effectiveness of the modeling methods for all components in addition to ED bars. HBD2 chooses the reinforcing steel with a fuse length as the dissipation element. HBD1 and s-SCP(I-ED) dissipate energy by the internal reinforcing steel, the corresponding unbonded length is $50 \mathrm{~mm}$ and 100 $\mathrm{mm}$, respectively. More detailed information about these specimens can be found in 
reference (Palermo et al. 2007; Guo et al, 2012).

160

As shown in Fig. 2, the numerical hysteretic curves are compared with the test

161

results. For specimen PT1 as shown in Fig. 2(a), the simulated initial stiffness is slightly

162

larger than the test result and the simulated strength was slightly lower. Besides,

because the elastic beam-column element is adopted to model the column, the simulated

164

165

166

167

168

169

170

171

172

173

hysteretic curve is unable to reflect the little energy dissipation during the cyclic loading.

On the whole, the FE result matches well with the test result, which suggests that the simulation techniques except for ED bars are effective.

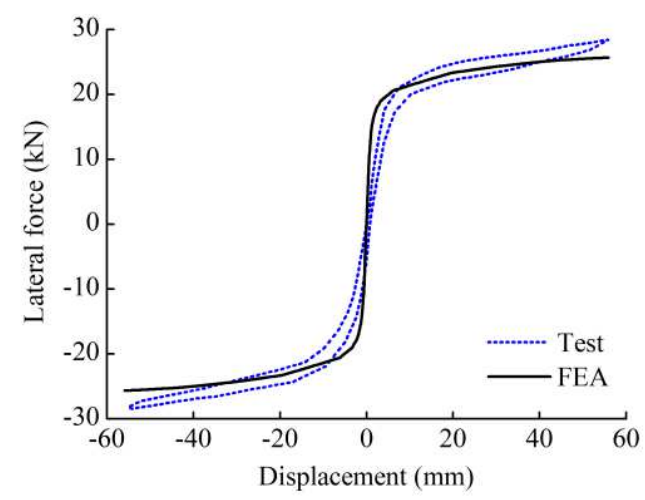

(a) PT1

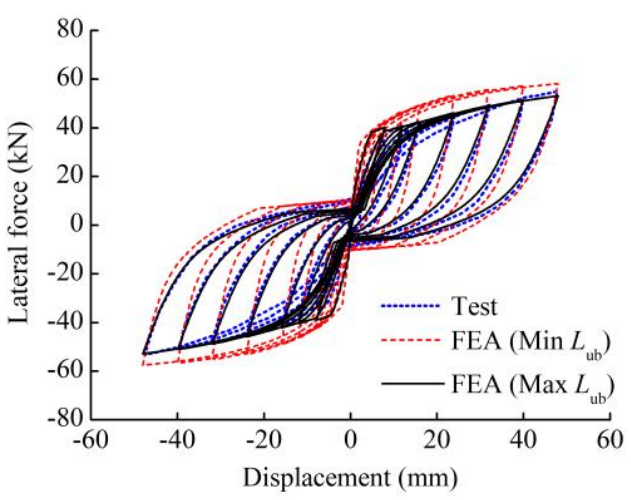

(c) HBD1

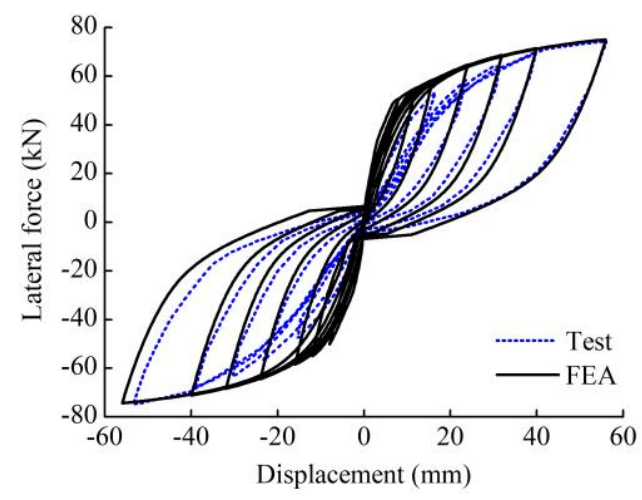

(b) HBD2

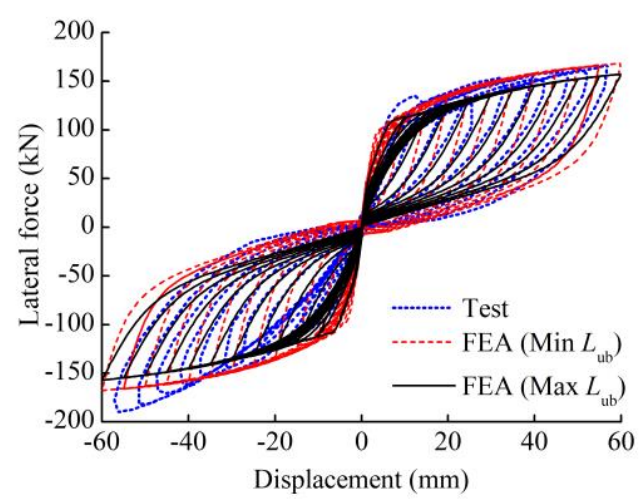

(d) s-SCP(I-ED)

Fig. 2 Comparisons of the numerical hysteretic curve with the test results

Due to the reinforcing steel in specimen HBD2 has a fuse length of $50 \mathrm{~mm}$, strain will be concentrated on the fuse segment, so $L_{\mathrm{ub}}$ is set to $50 \mathrm{~mm}$. The hysteretic curve 
based on FEA is plotted in Fig. 2(b). As for specimens HBD1 and s-SCP(I-ED), detailed comparisons between test and simulation results are presented in Fig. 2(c) and (d). The red and black curves represent the simulation results corresponding to the minimum $L_{\mathrm{ub}}$ and the maximum $L_{\mathrm{ub}}$, respectively. The lateral strength of the red curves is slightly larger than the black curves, it is because a smaller $L_{\mathrm{ub}}$ will generate a larger strain under the same joint opening, larger strain leads to larger dissipation force. As a result, the lateral strength is improved. Meanwhile, the residual displacement per loop of the red curves is also larger than the black curves, detailed comparisons are plotted in Fig. 3. On the one hand, this phenomenon can be explained from the perspective of larger dissipation force which weakens the self-centering capacity of the piers. On the other hand, the increase of $L_{\mathrm{ub}}$ will decrease the slope of unloading path significantly and thus diminish the residual displacement as shown in Fig. 2(c) and (d). The latter reason is more important, because the improvement of dissipation force is very limited.

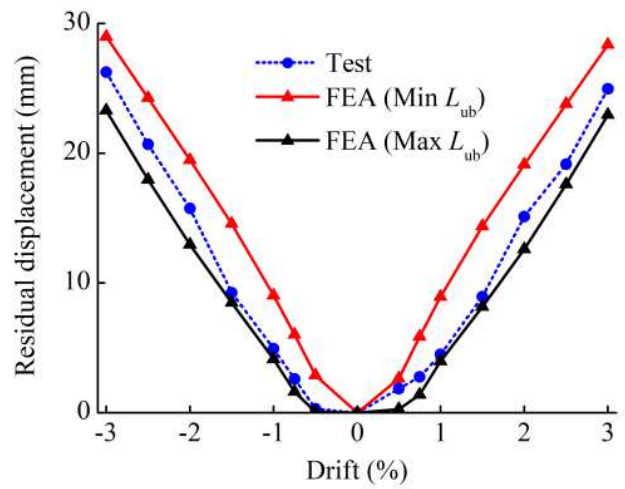

(a) HBD1

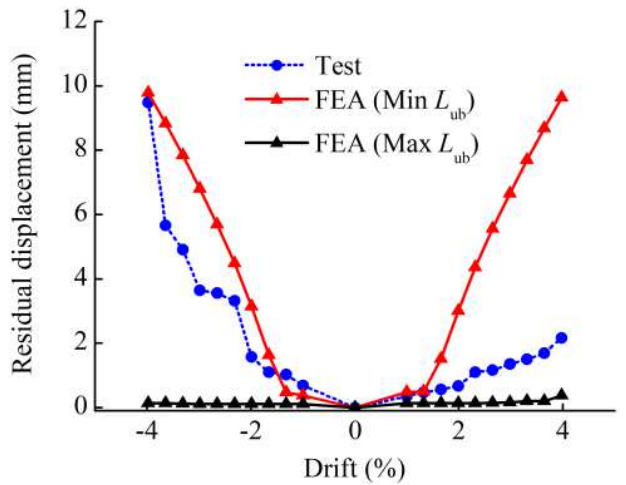

(b) s-SCP(I-ED)

Fig. 3 Comparison of the numerical residual displacement with the test results

Based on the above analysis and Fig. 3, it can be concluded that the proposed simulation method is effective. However, there is uncertainty of $L_{\mathrm{ub}}$ in the modeling process, a conservative result of residual displacement will be obtained generally if the 
strain penetration is not considered, and it is highly possible to underestimate the residual displacement if using Eq. (3) to calculate the equivalent unbonded length.

\section{Governing design parameters for residual displacement}

Two design parameters, the SC factor and ED parameter, are believed to have governing influence on the residual displacement.

\subsection{Definition and calculation of SC factor}

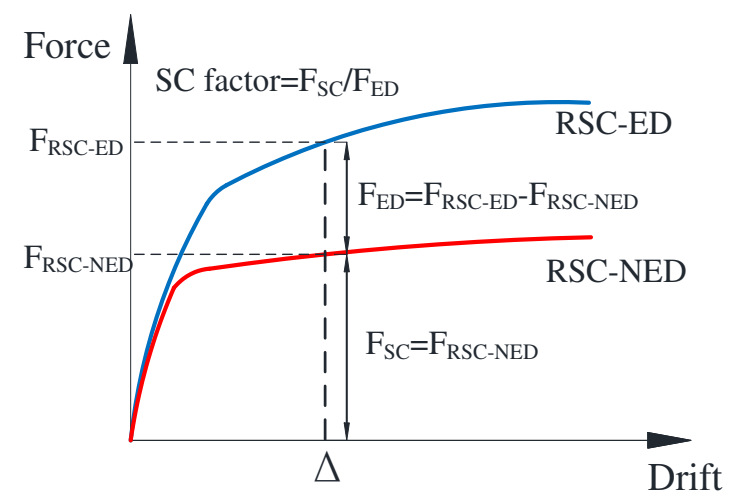

Fig. 4 Definition and calculation of SC factor

Several researchers have put forward different SC factor for evaluating the self-centering capacity of RSC columns. Hieber et al. (2005) proposed the re-centering ratio which is equal to the ratio between the total axial force (including the gravity force and initial prestressing force) and the yielding force of ED bars. The self-centering capacity of bridge columns at different drifts is usually different, while the re-centering ratio is a constant for an RSC column.

The contribution ratio $\lambda_{\mathrm{SC}}$ is another SC factor and it is typically adopted in the design of RSC systems (Palermo et al. 2007; Wang et al. 2019; Weng et al. 2010). $\lambda_{\mathrm{SC}}$ in its generic form represents the force or moment ratio between the self-centering contribution and the energy dissipation contribution, as shown in Eq. (7). 


$$
\lambda_{\mathrm{SC}}=\frac{M_{\text {self-centering }}}{M_{\text {dissipation }}}=\frac{F_{\text {self-centering }}}{F_{\text {dissipation }}}
$$

The self-centering and energy dissipation contribution can be derived from the

214 calculation process is still relatively complicated. What's more, $\lambda_{\mathrm{SC}}$ is obtained from

215 theoretical calculation, while the residual displacement is determined by simulation. In

216 order to reduce error, it is better that using simulation method to measure the

217 self-centering performance index. For this reason, the SC factor $\lambda_{\mathrm{SC}}$ used in this study

218 is defined as follows:

219

$$
\lambda_{\mathrm{SC}}=\frac{F_{\mathrm{SC}}}{F_{\mathrm{ED}}}
$$

220 where $F_{\mathrm{SC}}$ is the self-centering contribution provided by gravity load and PT tendons,

221 and $F_{\mathrm{ED}}$ is the energy dissipation contribution provided by ED bars. As shown in Fig. 4,

222 the calculation of $\lambda_{\mathrm{SC}}$ requires the following two steps:

223 (1) Establish the numerical model of RSC-ED columns and conduct a pushover analysis, 224 then the force-displacement curve can be obtained. The force $F_{\text {RSC-ED includes the }}$ 225 self-centering and energy dissipation contribution.

226 (2) Delete the ED bar elements from the existing numerical model of the RSC-ED 227 column and perform a pushover analysis again, then the force-displacement curve which 228 only contain the self-centering contribution is obtained. Therefore, the energy dissipation contribution $F_{\mathrm{ED}}$ can be derived as:

$$
F_{\mathrm{ED}}=F_{\text {RSC-ED }}-F_{\text {RSC-NED }}
$$




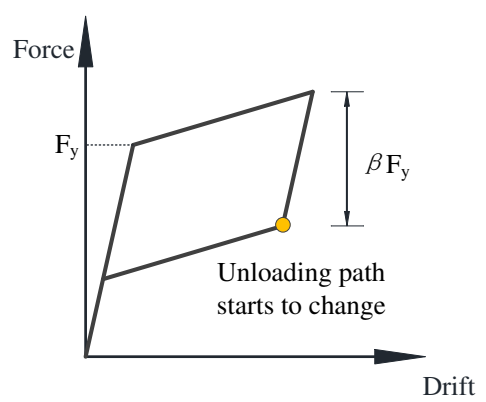

(a) Self-centering model

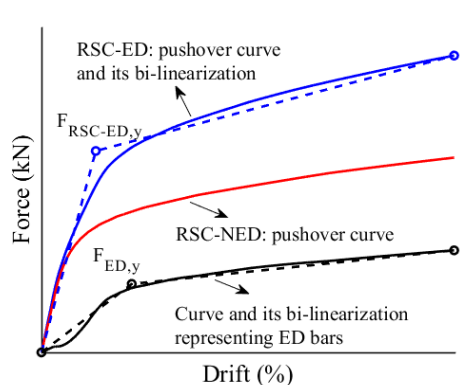

(e) Calculation of energy dissipation parameter

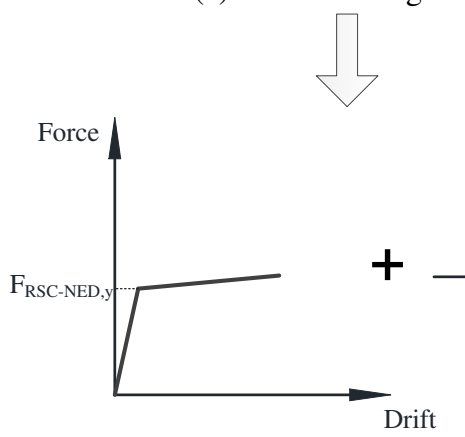

(b) Bilinear elastic model for RSC-NED columns

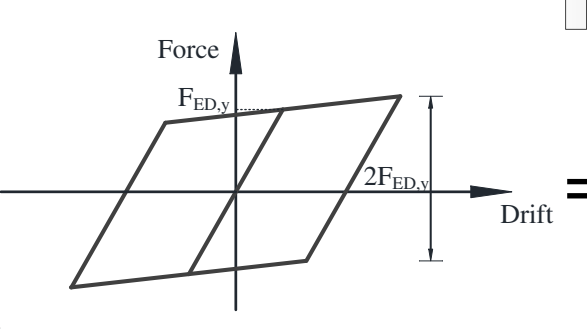

(c) bilinear elasto-plastic model for ED bars

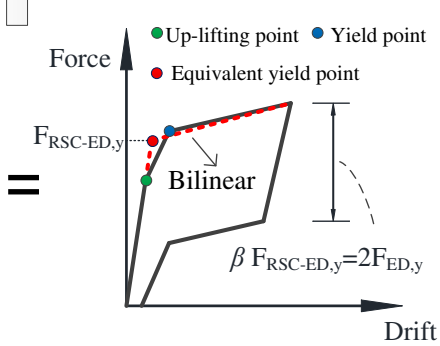

(d) Flag-shaped hysteresis of RSC-ED columns

Fig. 5 Definition and calculation of ED parameter

The second governing design parameter is ED parameter. The cyclic behavior of RSC columns can be simplified into a flag-shaped hysteretic model as shown in Fig. 5(a). The ED parameter $\beta$ is a significant parameter in this model, it not only reflects the energy dissipation capacity of the model, but also controls the where the unloading path starts to change. The smaller the ED parameter is, the earlier the unloading path changes, leading to smaller residual displacement. Hence, it can be predicted that the ED parameter has a non-ignorable influence on the residual displacement, while the recent researches related to the residual displacement of RSC systems all did not consider it.

The self-centering model is so ideal that it is unable to capture the residual displacement in fact. Implementing two rotational springs in parallel with appropriate hysteretic models is another simplified simulation method. The RSC column without 
ED bars is modelled by a bilinear elastic model, as shown in Fig.5 (b). The ED bar is simulated using a bilinear elasto-plastic model, as shown in Fig.5 (c). With the coaction of the two springs, the RSC column presents a trilinear skeleton curve to be exact, there is a stiffness reduction after the column is lifted up. Since the stiffness reduction is very slight, the skeleton curve can be approximate to a bilinear one.

To extract the ED parameter, an equivalent linearization method is used. The ED parameter can be calculated as:

$$
\beta=\frac{2 F_{E D, y}}{F_{\text {RSC-ED,y }}}
$$

where $F_{\mathrm{ED}, y}$ is the yielding force of the bilinear elasto-plastic model; $F_{\mathrm{RSC}-\mathrm{ED}, \mathrm{y}}$ is the effective yielding strength of the bridge column, as shown in Fig. 5(d).

Eq. (10) can be expressed approximately as:

$$
\beta \approx \frac{2 F_{E D, \mathrm{y}}}{F_{E D, \mathrm{y}}+F_{\mathrm{RSC}-\mathrm{NED}, \mathrm{y}}}=\frac{2}{1+F_{\mathrm{RSC}-\mathrm{NED}, \mathrm{y}} / F_{E D, \mathrm{y}}}=\frac{2}{1+\lambda_{\mathrm{SC}, \mathrm{y}}}
$$

where $F_{\mathrm{RSC}-\mathrm{NED}, \mathrm{y}}$ is the yielding force of the bilinear elastic model, $\lambda_{\mathrm{SC}, \mathrm{y}}$ is the $\mathrm{SC}$ factor that corresponds to the yield displacement. It can be found that the value of $\beta$ is relatively stable, and it is smaller than 1 when the value of $\lambda_{\mathrm{sc}, y}$ exceeds 1 . As shown in Fig. 5(e), the calculation of $\beta$ requires the following two steps:

(1) Establish the FE model of an RSC-ED column and perform a pushover analysis, then the obtained pushover curve is bilinearized according to the equal energy principle, the parameter $F_{\text {RSC-ED,y }}$ can be determined.

(2) Delete the ED bar elements from the FE model and carry out a pushover analysis again, then the force-displacement curve representing the energy dissipation 
contribution can be plotted by subtraction. Conduct an equivalent linearization again

267 and the parameter $F_{E D, y}$ is obtained.

268

269

270

271

272

273

274

275

276

277

278

279

280

281

282

283

284

285

286

287

\section{Fractional factorial analysis}

In the actual construction of RSC columns, the key design parameters are presented in the form of aspect ratio $\lambda$, concrete strength $f_{\mathrm{c}}$, PT tendon ratio $\rho_{\mathrm{PT}}$, axial-load ratio $\left(\eta_{\mathrm{G}}, \eta_{\mathrm{PT}}\right)$ caused by gravity load $P_{\mathrm{G}}$ and PT force $P_{\mathrm{PT}}$, ED bar ratio $\rho_{\mathrm{ED}}$, yield stress of ED bars $f_{\mathrm{y}}$ and unbonded length $L_{0}$. It should be noted that the non-dimensional parameters, the SC factor and ED parameter, can be regarded as the comprehensive embodiment of these key design parameters. This part of study uses fractional factorial analysis to discuss the effect of each parameter on the SC factor and ED parameter at different drifts.

\subsection{Design parameters of reference specimen}

In the factorial analysis study, the reference specimen RS chooses the prototype of specimen HBD1, the specimen HBD1 is $1 / 3$ scaled, but the design parameters of specimen RS are not strictly converted by a scale of 1:3 according to those of specimen HBD1, as shown in Table 2. For example, in order to ensure the ED bars have enough deformation capacity at larger loading drift, the value of $\mathrm{L}_{0}$ of the specimen RS is set to $300 \mathrm{~mm}$ rather than $150 \mathrm{~mm}$. The prototype pier of specimen HBD1 has a total mass of $180 \mathrm{t}$, but the gravity force was not applied in the test due to the limitation of the experimental prestressing, the value of $P_{\mathrm{G}}$ of the specimen RS is $1800 \mathrm{kN}$. Meanwhile, $P_{\mathrm{G}}$ will enhance the self-centering capacity of the specimen RS, which may lead to no residual displacement. Therefore, the value of $P_{\mathrm{PT}}$ is set to $600 \mathrm{kN}$ rather than 1800 
$\mathrm{kN}$.

Table 2 Comparison of the design parameters of specimens HBD1 and RS

\begin{tabular}{ccccccccccccccccc}
\hline Specimen & Width (mm) & $\lambda$ & $f_{c}(\mathrm{MPa})$ & $\mathrm{ED} \mathrm{bar}$ & $\rho_{E D}(\%)$ & $f_{\mathrm{y}}(\mathrm{MPa})$ & $L_{0}(\mathrm{~mm})$ & $\mathrm{PT}$ tendon & $\rho_{\mathrm{PT}}(\%)$ & $P_{\mathrm{G}}(\mathrm{kN})$ & $\eta_{\mathrm{G}}$ & $P_{\mathrm{PT}}(\mathrm{kN})$ & $\eta_{\mathrm{PT}}$ \\
\hline HBD1 & 350 & 4.57 & 54.1 & $4 \mathrm{D} 16$ & 0.66 & 304 & 50 & $2 \times 99 \mathrm{~mm}^{2}$ & 0.16 & 0 & 0 & 200 & 0.03 \\
RS & 1050 & 4.57 & 54.1 & $20 \mathrm{D} 22$ & 0.69 & 304 & 300 & $12 \mathrm{D} 15.2$ & 0.2 & 1800 & 0.03 & 600 & 0.01 \\
\hline
\end{tabular}

290

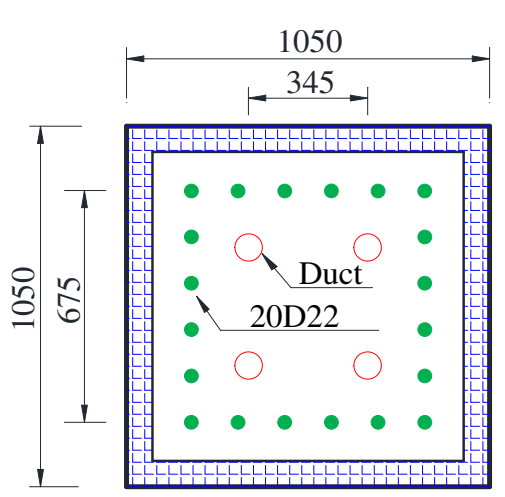

(a) Cross-section

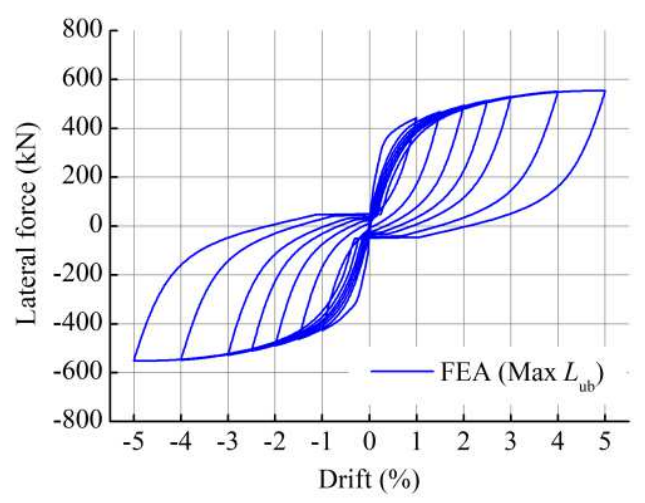

(b) hysteretic curve

Fig. 6 Cross-section and cyclic behavior of specimen RS (Unit: $\mathrm{mm}$ )

Fig. 6(a) shows the cross-section of the specimen RS, each duct holds 4 PT tendons, and the diameter and tensile strength of each PT tendon are $15.2 \mathrm{~mm}$ and $1860 \mathrm{MPa}$, respectively. The PT tendon ratio can be easily adjusted by changing the number of PT tendons in each duct, the ED bar ratio can be changed by altering the diameter of ED bars in the following study. The hysteretic curve of the specimen RS is plotted in Fig. 6(b). For specimen HBD1, the simulation result corresponding to the maximum value of $L_{\mathrm{ub}}$ matches better with the test result, as shown in Fig. 2(c), so the maximum $L_{\mathrm{ub}}$ is adopted in this part.

\subsection{Two-level fractional design}

The purpose of of this fractional factorial analysis is to evaluate the importance of the key design parameters to the residual displacement of RSC columns. Table 3 shows the key parameters and the two levels of each parameter. The ranges of the factors are 
determined by the investigation of 19 RSC column specimens (Palermo et al. 2007; Ou et al. 2010; Tong et al. 2019; Bu et al. 2016; Marriott et al. 2009), the statistical results are also reported in Table 3. To prevent the PT tendon yields under cyclic loading, the value of $P_{\mathrm{d}}$ corresponding to its high level is set to 0.4 , and the maximum loading drift is $4 \%$.

Factorial analysis is used often when multiple factors exist in determining an output. However, the full factorial analysis requires a great number of runs if many factors are taken into account, which may become computationally expensive. In this study, the analysis includes eight factors and each factor has two levels, a complete factorial analysis needs 256 runs. In order to improve the efficiency, one-eighth factorial analysis is performed, which decreased the required runs to $2^{8-3}$ for a total of 32 .

The approach Montgomery proposed (2008) is used to perform the fractional factorial analysis. The construction of a one- eighth factorial analysis consists of two parts. The first part is a basic design, which contains a complete $2^{8-3}$ fractional factorial combination (the first five columns in Table 4). The other part includes three generators (the last three columns in Table 4) which determines the factors that are not included in the basic design. - and + are the symbols of low level and high level, respectively. The levels of the last three factors are determined by using generating relations.

Table 3 Two levels of the considered factors

\begin{tabular}{ccccccccc}
\hline \multirow{2}{*}{ Level } & $\lambda$ & $f_{\mathrm{c}}$ & $P_{\mathrm{d}}$ & $\rho_{\mathrm{PT}}$ & $\eta_{\mathrm{G}}$ & $L_{\mathrm{o}}(\mathrm{mm})$ & $f_{\mathrm{y}}(\mathrm{MPa})$ \\
& $(\mathrm{A})$ & $(\mathrm{B})$ & $(\mathrm{C})$ & $(\mathrm{D})$ & $(\mathrm{E})$ & $(\mathrm{F}=\mathrm{ABC})$ & $(\mathrm{G}=\mathrm{ABD})$ & $(\mathrm{H}=\mathrm{BCDE})$ \\
\hline Range & $4.42 \sim 5.29$ & $32 \sim 65.9$ & $0.12 \sim 0.51$ & $0.13 \% \sim 0.65 \%$ & $0 \sim 0.1$ & $50 \sim 400$ & $300 \sim 600$ & $0.26 \% \sim 1.03 \%$ \\
- (low) & 3.5 & 30 & 0.2 & $0.20 \%$ & 0.02 & 150 & 300 & $0.46 \%$ \\
+ (high) & 6 & 60 & 0.4 & $0.60 \%$ & 0.1 & 450 & 600 & $1.12 \%$ \\
\hline
\end{tabular}

Note: $P_{\mathrm{d}}$ is the ratio between the initial stress of a PT tendon and its yield stress. 
Table $42^{8-3}$ fractional factorial design

\begin{tabular}{|c|c|c|c|c|c|c|c|c|}
\hline \multirow{2}{*}{$\begin{array}{c}\text { Case } \\
\text { (Level) }\end{array}$} & \multicolumn{5}{|c|}{ Basic design } & \multicolumn{3}{|c|}{ Generated from basic design } \\
\hline & $\begin{array}{c}\lambda \\
\text { (A) }\end{array}$ & $\begin{array}{l}f_{c} \\
(\mathrm{~B})\end{array}$ & $\begin{array}{l}P_{\mathrm{d}} \\
(\mathrm{C})\end{array}$ & $\begin{array}{l}\rho_{\mathrm{PT}} \\
(\mathrm{D})\end{array}$ & $\begin{array}{l}\eta_{\mathrm{G}} \\
(\mathrm{E})\end{array}$ & $\begin{array}{c}L_{0} \\
(\mathrm{~F}=\mathrm{ABC})\end{array}$ & $\begin{array}{c}f_{\mathrm{y}} \\
(\mathrm{G}=\mathrm{ABD})\end{array}$ & $\begin{array}{c}\rho_{\mathrm{ED}} \\
(\mathrm{H}=\mathrm{BCDE})\end{array}$ \\
\hline 1 & -1 & -1 & -1 & -1 & -1 & -1 & -1 & 1 \\
\hline 2 & 1 & -1 & -1 & -1 & -1 & 1 & 1 & 1 \\
\hline 3 & -1 & 1 & -1 & -1 & -1 & 1 & 1 & -1 \\
\hline 4 & 1 & 1 & -1 & -1 & -1 & -1 & -1 & -1 \\
\hline 5 & -1 & -1 & 1 & -1 & -1 & 1 & -1 & -1 \\
\hline 6 & 1 & -1 & 1 & -1 & -1 & -1 & 1 & -1 \\
\hline 7 & -1 & 1 & 1 & -1 & -1 & -1 & 1 & 1 \\
\hline 8 & 1 & 1 & 1 & -1 & -1 & 1 & -1 & 1 \\
\hline 9 & -1 & -1 & -1 & 1 & -1 & -1 & 1 & -1 \\
\hline 10 & 1 & -1 & -1 & 1 & -1 & 1 & -1 & -1 \\
\hline 11 & -1 & 1 & -1 & 1 & -1 & 1 & -1 & 1 \\
\hline 12 & 1 & 1 & -1 & 1 & -1 & -1 & 1 & 1 \\
\hline 13 & -1 & -1 & 1 & 1 & -1 & 1 & 1 & 1 \\
\hline 14 & 1 & -1 & 1 & 1 & -1 & -1 & -1 & 1 \\
\hline 15 & -1 & 1 & 1 & 1 & -1 & -1 & -1 & -1 \\
\hline 16 & 1 & 1 & 1 & 1 & -1 & 1 & 1 & -1 \\
\hline 17 & -1 & -1 & -1 & -1 & 1 & -1 & -1 & -1 \\
\hline 18 & 1 & -1 & -1 & -1 & 1 & 1 & 1 & -1 \\
\hline 19 & -1 & 1 & -1 & -1 & 1 & 1 & 1 & 1 \\
\hline 20 & 1 & 1 & -1 & -1 & 1 & -1 & -1 & 1 \\
\hline 21 & -1 & -1 & 1 & -1 & 1 & 1 & -1 & 1 \\
\hline 22 & 1 & -1 & 1 & -1 & 1 & -1 & 1 & 1 \\
\hline 23 & -1 & 1 & 1 & -1 & 1 & -1 & 1 & -1 \\
\hline 24 & 1 & 1 & 1 & -1 & 1 & 1 & -1 & -1 \\
\hline 25 & -1 & -1 & -1 & 1 & 1 & -1 & 1 & 1 \\
\hline 26 & 1 & -1 & -1 & 1 & 1 & 1 & -1 & 1 \\
\hline 27 & -1 & 1 & -1 & 1 & 1 & 1 & -1 & -1 \\
\hline 28 & 1 & 1 & -1 & 1 & 1 & -1 & 1 & -1 \\
\hline 29 & -1 & -1 & 1 & 1 & 1 & 1 & 1 & -1 \\
\hline 30 & 1 & -1 & 1 & 1 & 1 & -1 & -1 & -1 \\
\hline 31 & -1 & 1 & 1 & 1 & 1 & -1 & -1 & 1 \\
\hline 32 & 1 & 1 & 1 & 1 & 1 & 1 & 1 & 1 \\
\hline
\end{tabular}

\subsection{Results of factorial analysis}

Based on the earthquake damage investigation results, the Japan Road Association

328 (JRA) code proposed a residual drift limitation of $1 \%$ for $\mathrm{RC}$ columns to measure

329 whether the columns could be repaired or not (Japan Road Association, 2002). If the 

parameter at $1 \%$ drift are not concerned.

333

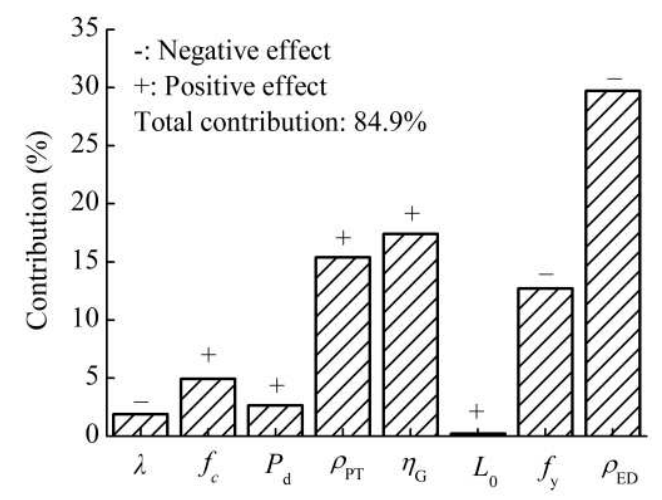

(a) $2 \%$ drift

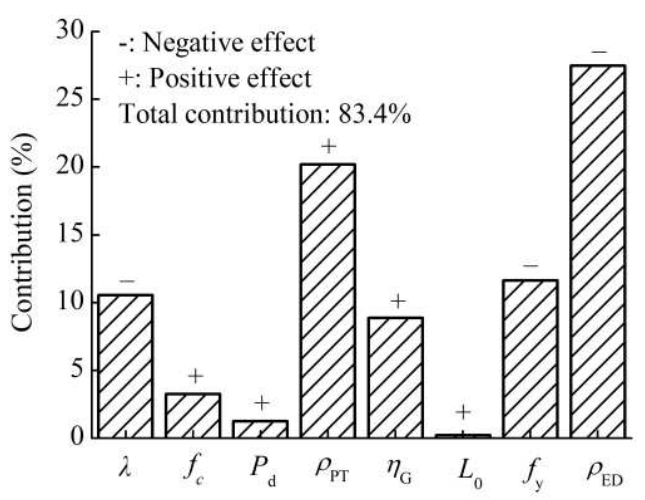

(c) $4 \%$ drift

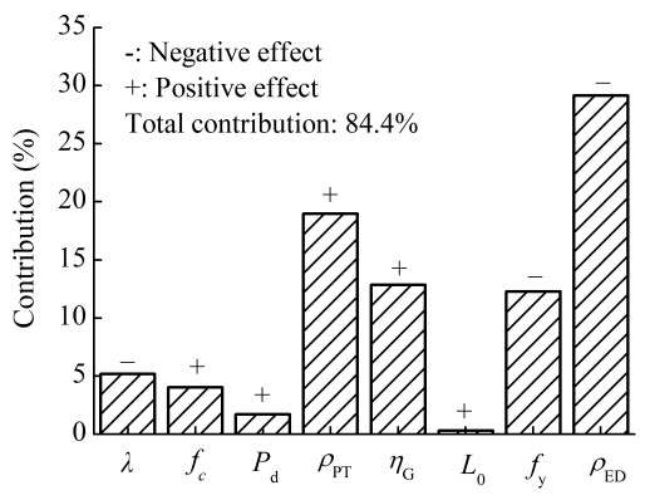

(b) $3 \%$ drift

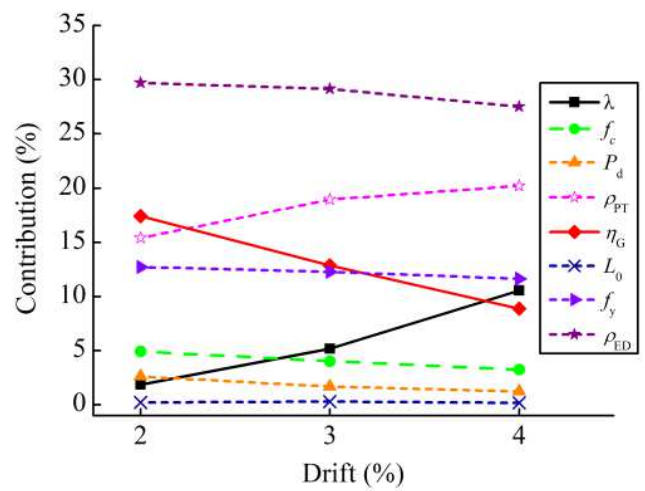

(d) Change of contribution

Fig. 7 Contribution of key parameters to SC factor under different drifts

The effect of each key parameter on the SC factor at $2 \%, 3 \%$ and $4 \%$ drift is compared as shown in Fig. 7. Except for $\lambda, f_{\mathrm{y}}$ and $\rho_{\mathrm{ED}}$, the else five parameters have positive influence on the SC factor. At the considered levels of the parameters, the most important parameters is $\rho_{\mathrm{ED}}, f_{\mathrm{y}}, \rho_{\mathrm{TP}}$ and $\eta_{\mathrm{G}}$, the contribution of $L_{0}$ can be neglected. The change of contribution provided by each parameter is presented in Fig. $7(\mathrm{~d})$, it can be be observed that the change of the contribution provided by $\lambda$ and $\eta_{\mathrm{G}}$ is the most notable. With the increase of drift, the contribution of $\lambda$ increases from $1.9 \%$ 
to $10.5 \%$, while the contribution of $\eta_{\mathrm{G}}$ declines from $17.4 \%$ to $8.9 \%$. This is because the

which drift is considered, no intense interaction between the parameters is observed.

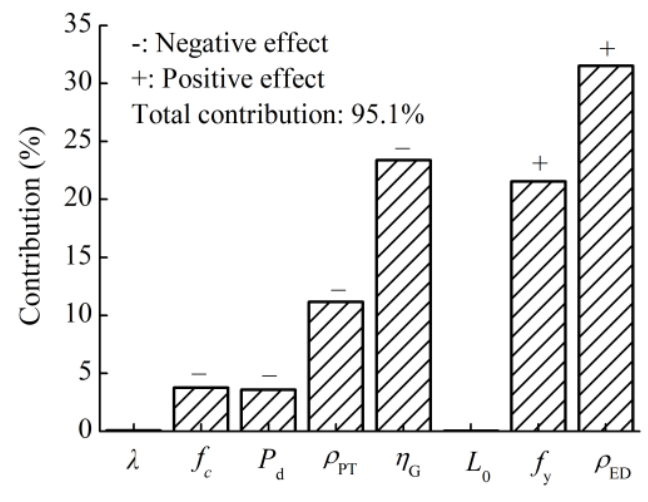

(a) $2 \%$ drift

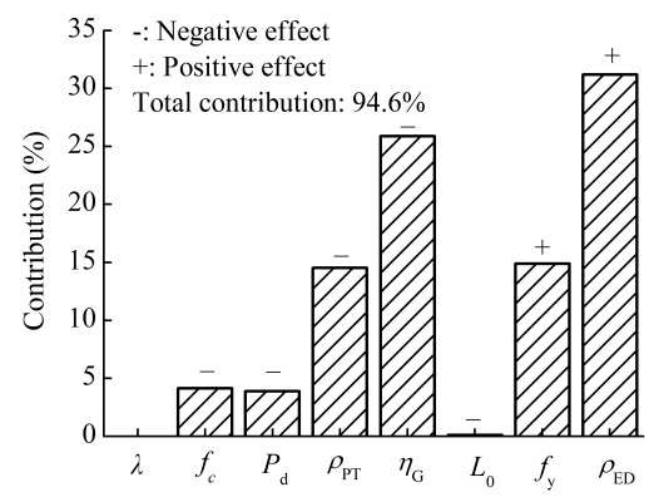

(c) $4 \%$ drift

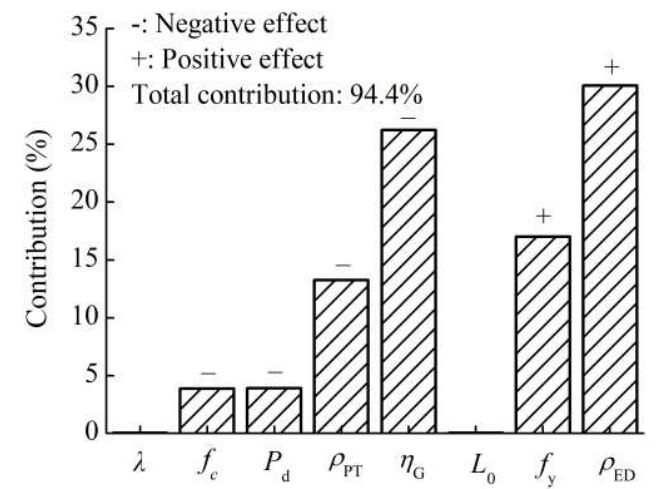

(b) $3 \%$ drift

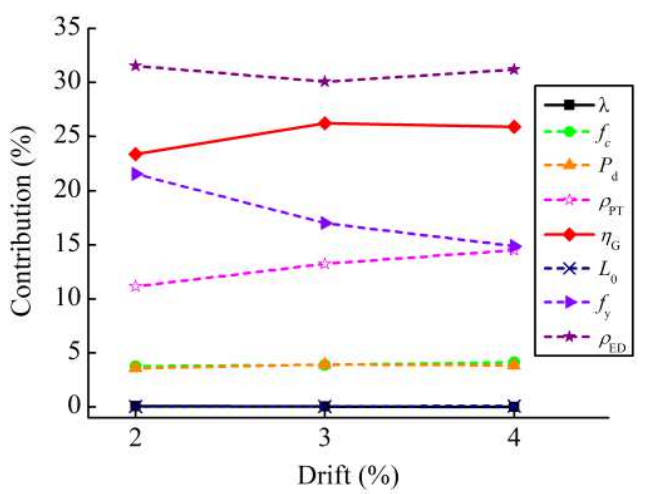

(d) Change of contribution

Fig. 8 Contribution of key parameters to ED parameter under different drifts

As shown in Fig. 8, the contribution of each factor to the ED parameter at 2\%, 3\% and $4 \%$ drift is compared. $f_{\mathrm{c}}, P_{\mathrm{d}}, \rho_{\mathrm{TP}}$ and $\eta_{\mathrm{G}}$ have a negative effect, $f_{\mathrm{y}}$ and $\rho_{\mathrm{ED}}$ have a positive effect, the effect of $\lambda$ and $L_{0}$ is approximate to zero. The most significant parameters are $\rho_{\mathrm{ED}}, f_{\mathrm{y}}, \eta_{\mathrm{G}}$ and $\rho_{\mathrm{TP}}$. As shown in Fig. $8(\mathrm{~d})$, the contribution of these parameters excluding $f_{\mathrm{y}}$ basically remains the same, the 
377 where $D_{\text {-res }}$ and $D_{\text {res }}$ are the residual drift corresponding to the negative and positive

contribution of $f_{\mathrm{y}}$ decreases from $21.5 \%$ to $14.9 \%$ as the drift increases from $2 \%$ to $4 \%$. On the other hand, the total contribution at the three loading drifts all reaches $94 \%$, it can be concluded that the ED parameter is dominated by the effect of single factor and the interaction between the factors is very slight. Here, the ED parameter $\beta$ is fitted with a linear regression model which can be expressed as follows:

$$
\beta=a_{0}+a_{1} x_{1}+a_{2} x_{2}+a_{3} x_{3}+a_{4} x_{4}+a_{5} x_{5}+a_{6} x_{6}
$$

where $x_{1}, x_{2}, x_{3}, x_{4}, x_{5}$ and $x_{6}$ are the normalized parameters representing the effect of $f_{\mathrm{c}}, P_{\mathrm{d}}, \rho_{\mathrm{TP}}, \eta_{\mathrm{G}}, f_{\mathrm{y}}$ and $\rho_{\mathrm{ED}}$. For example, $x_{1}=(\lambda-45) / 15$. The normalized parameters range from -1 to 1 (corresponding to low and high levels). The obtained corresponding coefficients of the regression model are given in Table 5.

Table 5 Coefficient values of the regression model for $\beta$

\begin{tabular}{cccccccc}
\hline \multirow{2}{*}{ Drift } & \multicolumn{7}{c}{ Coefficients } \\
\cline { 2 - 8 } & $a_{0}$ & $a_{1}$ & $a_{2}$ & $a_{3}$ & $a_{4}$ & $a_{5}$ & $a_{6}$ \\
\hline $2 \%$ & 0.760 & -0.062 & -0.060 & -0.106 & -0.154 & 0.148 & 0.179 \\
$3 \%$ & 0.749 & -0.062 & -0.062 & -0.115 & -0.161 & 0.130 & 0.173 \\
$4 \%$ & 0.746 & -0.063 & -0.061 & -0.118 & -0.157 & 0.119 & 0.173 \\
\hline
\end{tabular}

\section{Formula to predict residual drift under cyclic loading}

The purpose of this part is exploring the effect of the SC factor and ED parameter on the distribution of the residual drift, and predicting the residual drift under cyclic loading. Due to there are two directions during a full cycle, the residual drift $D_{\text {res }}$ is defined as:

$$
D_{\text {res }}=\frac{D_{- \text {res }}+D_{+ \text {res }}}{2}
$$
loading directions, respectively. 


\subsection{Parametric study}

In order to obtain enough data to analyze the distribution of residual drift, a

parametric study is first carried out. Table 6 shows the all the specimens used in the

parametric study, the specimens are designed based on the specimen RS. Each specimen

has a special denotation which corresponding to a value of the parameter. For example,

for the aspect ratio $\lambda$, five specimens are designed and tagged with $\mathrm{A} 1, \mathrm{~A} 2, \mathrm{~A} 3, \mathrm{~A} 4$ and

A5. Among these tags, A1 corresponds to a value of 3.6.

Table 6 Denotation of specimens in parametric study

\begin{tabular}{ccc}
\hline Parameters & Denotation & Parameter values for each specimen \\
\hline$\lambda$ & A1, A2, A3, A4, A5 (A1-A5) & $3.6,4.6,5.5,6.5,7.4$ \\
$P_{\mathrm{d}}$ & PD1, PD2, PD3, PD4, PD5, PD6 (PD1-PD6) & $0.15,0.2,0.3,0.4,0.5,0.6$ \\
$\rho_{\mathrm{PT}}$ & PT1, PT2, PT3, PT4, PT5, PT6 (PT1-PT6) & $0.13 \%, 0.2 \%, 0.26 \%, 0.33 \%, 0.4 \%, 0.53 \%$ \\
$\eta_{\mathrm{G}}$ & $\mathrm{G} 1, \mathrm{G} 2, \mathrm{G} 3, \mathrm{G} 4, \mathrm{G} 5$ (G1-G5) & $0.03,0.045,0.06,0.075,0.091$ \\
$L_{0}$ & $\mathrm{~L} 1, \mathrm{~L} 2, \mathrm{~L} 3, \mathrm{~L} 4, \mathrm{~L} 5$ (L1-L5) & $300 \mathrm{~mm}, 400 \mathrm{~mm}, 500 \mathrm{~mm}, 600 \mathrm{~mm}, 700 \mathrm{~mm}$ \\
$f_{\mathrm{y}}$ & F1, F2, F3, F4, F5 (F1-F5) & $304 \mathrm{MPa}, 350 \mathrm{MPa}, 400 \mathrm{MPa}, 450 \mathrm{MPa}, 500 \mathrm{MPa}$ \\
$\rho_{\mathrm{ED}}$ & E1, E2, E3, E4, E5, E6 (E1-E6) & $0.46 \%, 0.69 \%, 0.89 \%, 1.12 \%, 1.46 \%, 2.28 \%$ \\
\hline
\end{tabular}

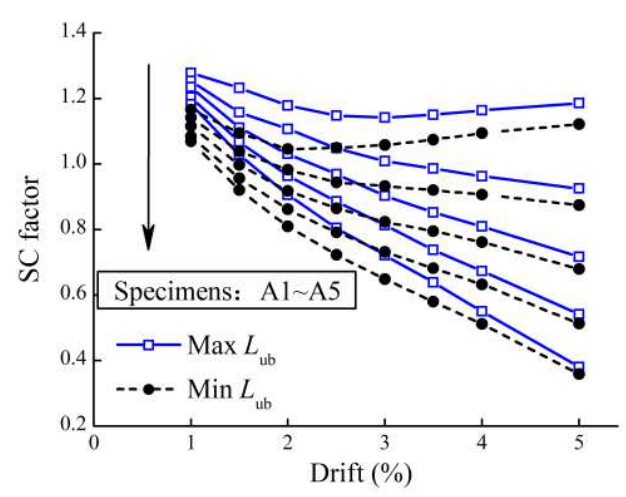

(a) Aspect ratio

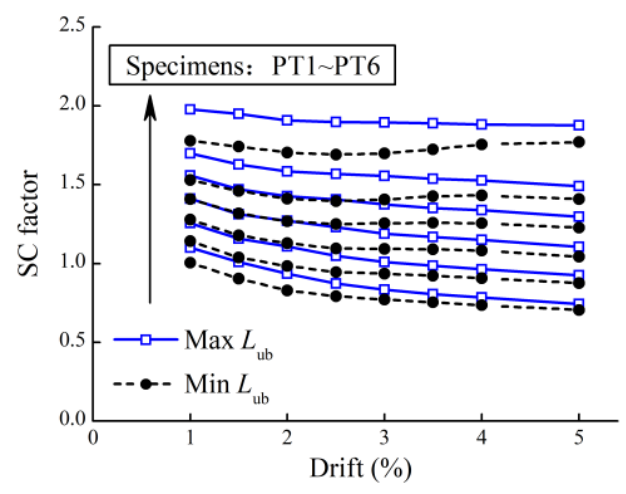

(c) PT tendon ratio

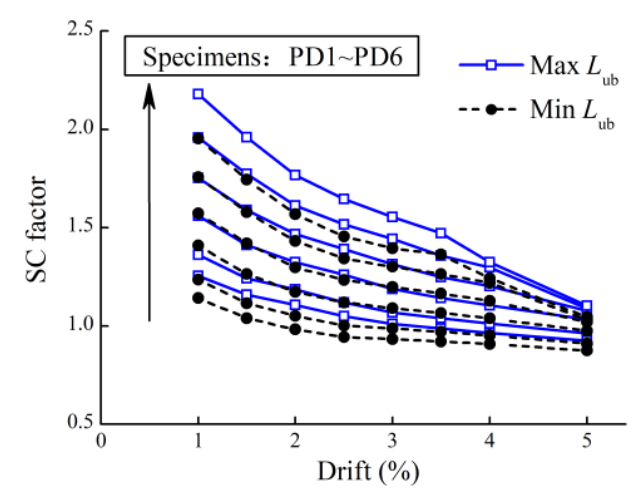

(b) Ratio between initial stress and yield stress

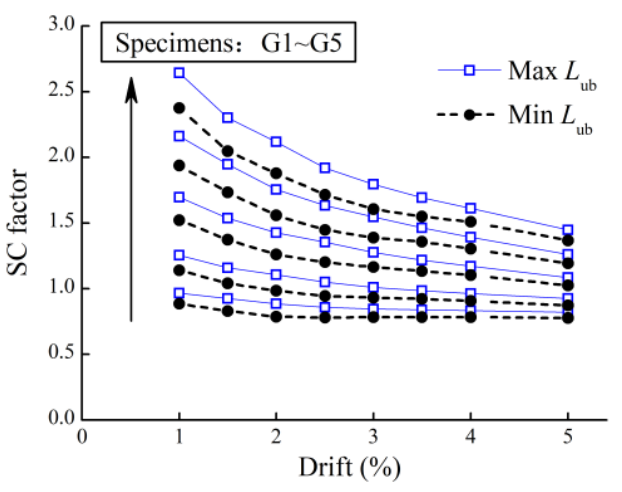

(d) Gravity axial load 


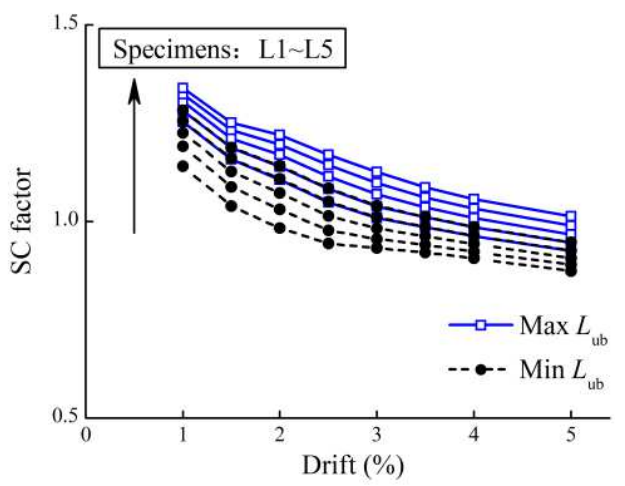

(e) Unbonded length of ED bars

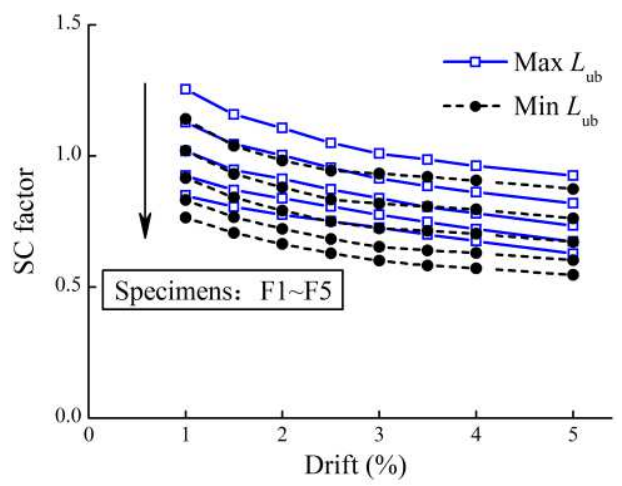

(f) Yield stress of ED bars

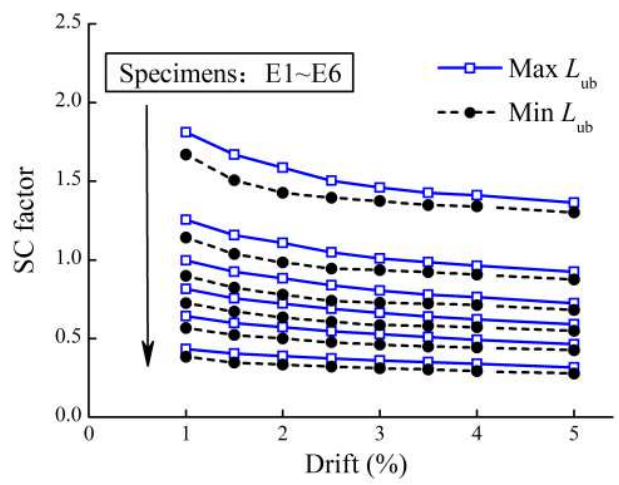

(g) ED bar ratio

Fig. 9 Influence of each parameter on SC factor

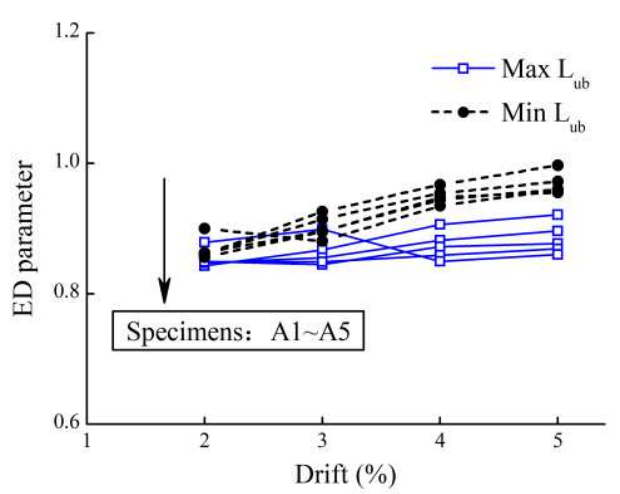

(a) Aspect ratio

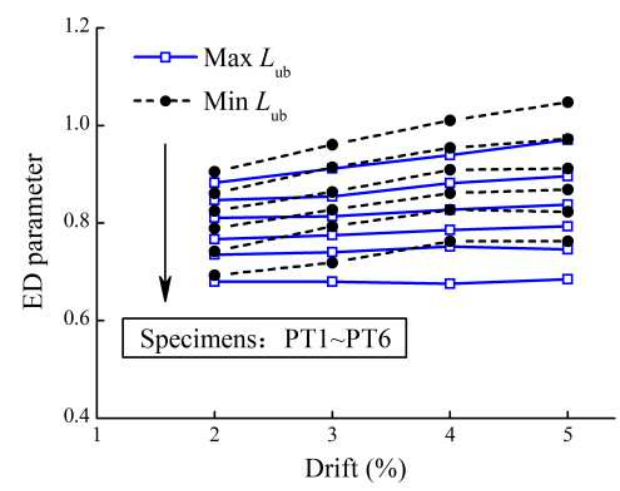

(c) PT tendon ratio

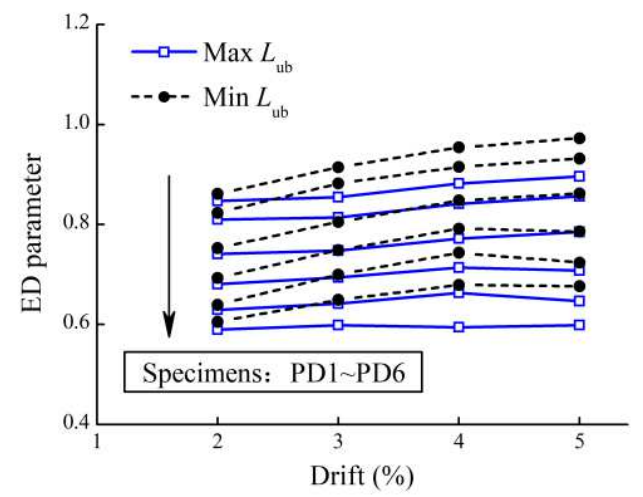

(b) Ratio between initial stress and yield stress

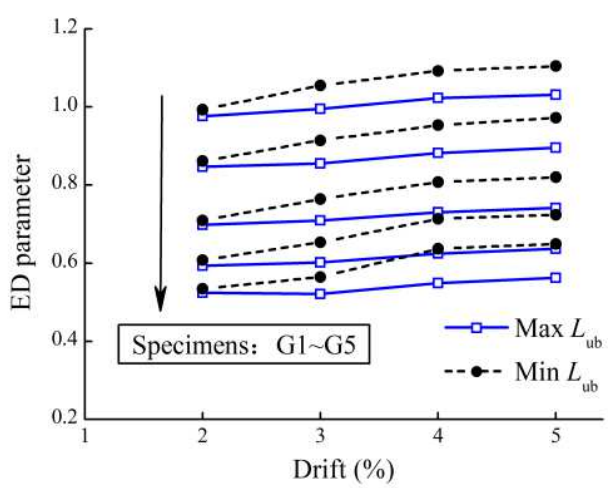

(d) Gravity axial load 


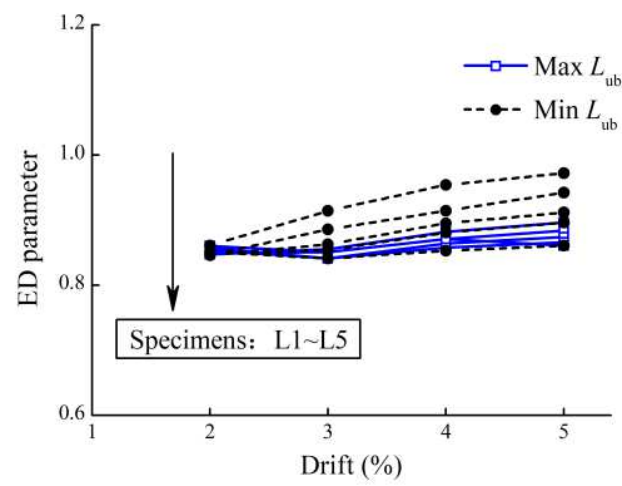

(e) Unbonded length of ED bars

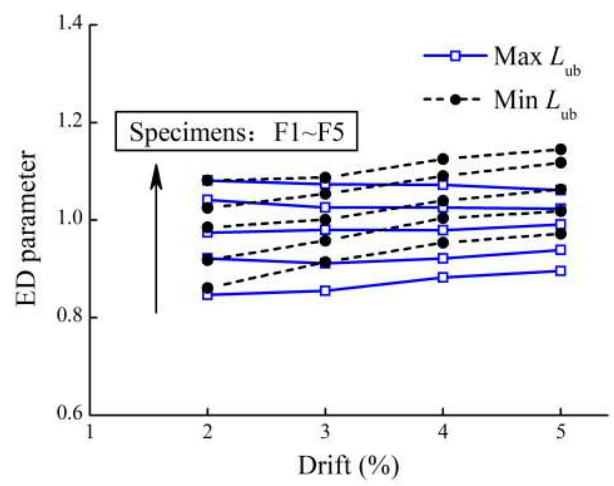

(f) Yield stress of ED bars

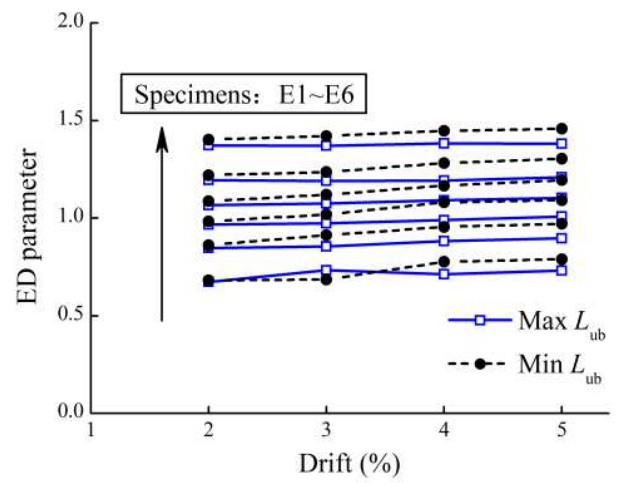

(g) ED bar ratio

Fig. 10 Influence of each parameter on ED parameter

Fig. 9 shows the influence of each parameter on the SC factor, the uncertainty of $L_{\mathrm{ub}}$ in the simulation process is considered. It can be concluded that the value of the SC factor corresponding to minimum $L_{\mathrm{ub}}$ is always smaller than that corresponding to maximum $L_{\mathrm{ub}}$, which indicates that the self-centering capacity of bridge columns will be underestimated if the strain penetration is not considered. The uncertainty of $L_{\mathrm{ub}}$ has little influence on the change tendency of the SC factor, the SC factor presents a downward trend as the drift increases.

As shown in Fig. 9(a), the five specimens (A1-A5) have a similar SC factor at 1\% drift. With the increase of drift, the SC factor of the specimen with a larger aspect ratio descends more rapidly because of the P- $\Delta$ effect. Specimen A1 is different from other specimens, its SC factor has a slight growth when the drift exceeds a certain value. 
417 their increase will enhance the SC factor as shown in Fig. 9(b), (c), (d) and (e). The 418 improvement effect of $P_{\mathrm{d}}$ and $\eta_{\mathrm{G}}$ on the SC factor is very similar and dependent on 419 the drift as shown in Fig. 9(b) and (d), a larger $P_{\mathrm{d}}$ and $\eta_{\mathrm{G}}$ can generate a larger SC 420 factor generally, but the self-centering capacity is not stable, which decreases sharply at 421 the drift increases. As shown in Fig.9 (c), it can be concluded that increasing the PT 422 tendon ratio is an effective method to strength the stability of the self-centering capacity. 423 Compared to $P_{\mathrm{d}}, \rho_{\mathrm{PT}}$ and $\eta_{\mathrm{G}}$, the effect of $L_{0}$ on the SC factor is very limited as 424 shown in Fig.9 (e). The value of $L_{0}$ increase from $300 \mathrm{~mm}$ to $700 \mathrm{~mm}$, while the 425 increase of SC factor does not exceed 0.3. Increasing $f_{\mathrm{y}}$ or $\rho_{\mathrm{ED}}$ is helpful to improve 426 the energy dissipation capacity, so their increase will reduce the SC factor as shown in 427 Fig. 9(f) and (g). There is a greatest reduction of the SC factor when $\rho_{\mathrm{ED}}$ increases from $0.46 \%$ to $0.69 \%$ as shown in Fig. $9(\mathrm{~g})$.

Similarly, Fig. 10 shows the influence of each parameter on the ED parameter, it can be observed that the ED parameter corresponding to the minimum $L_{\mathrm{ub}}$ is larger than that corresponding to the maximum $L_{\mathrm{ub}}$ commonly. With the increase of drift, the ED parameter shows a slight uptrend, it keeps stable on the whole and its largest growth does not reach 0.2. As shown in Fig. 10(a), (b), (c), (d) and (e), increasing $\lambda, P_{\mathrm{d}}, \rho_{\mathrm{PT}}$, $\eta_{\mathrm{G}}$ and $L_{0}$ are able to reduce the ED parameter, especially for $\eta_{\mathrm{G}}, P_{\mathrm{d}}$ and $\rho_{\mathrm{PT}}$, their reduction effect is more remarkable, and the effect of $\lambda$ and $L_{0}$ is relatively limited. Increasing $f_{\mathrm{y}}$ and $\rho_{\mathrm{ED}}$ are capable of improve the ED parameter as shown in Fig. 10(f) and (g). 


\subsection{Regression analysis}

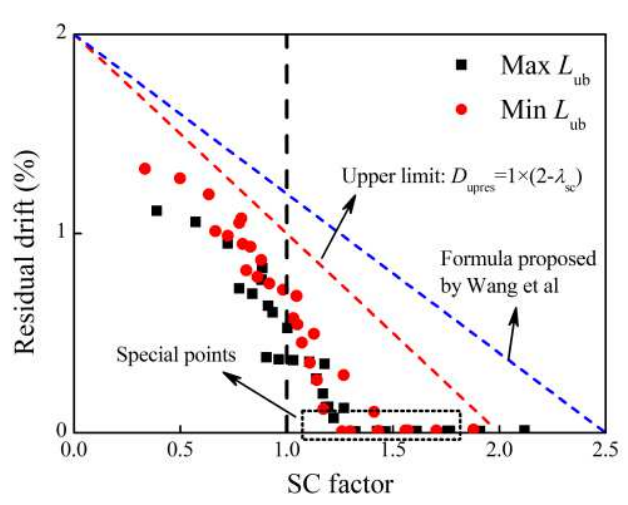

(a) $2 \%$ drift

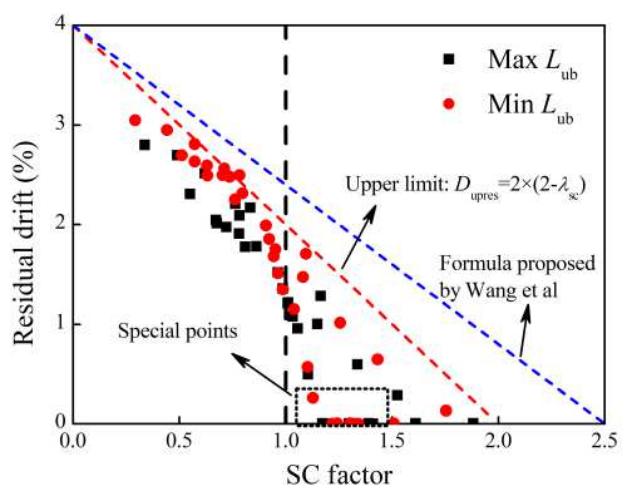

(c) $4 \%$ drift

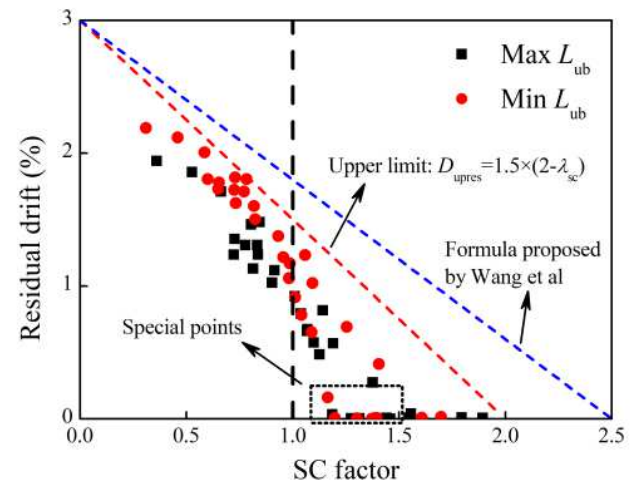

(b) $3 \%$ drift

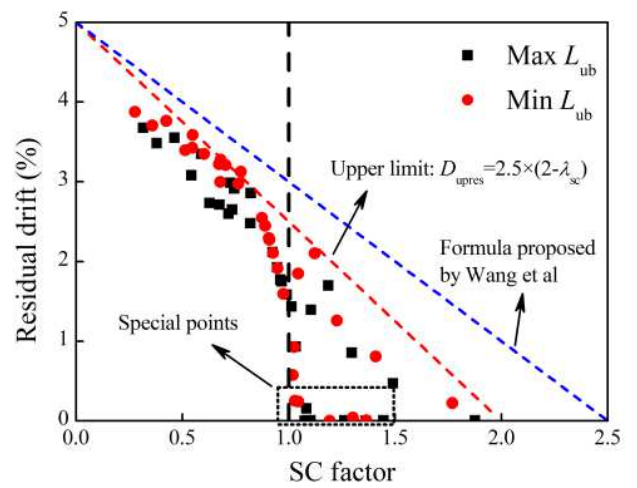

(d) $5 \%$ drift
442

443

444

445

446

447

448

449

450

451

452

Fig. 11 Effect of SC factor on residual drift distribution

As shown in Fig.11, the data obtained from the parameter analysis are collected to investigate the influence of the SC factor on the residual drift distribution. The black points correspond to the maximum $L_{\mathrm{ub}}$ and the red points corresponds to the minimum $L_{\mathrm{ub}}$. The red points are located at the upper boundary of the black points. The upper limit of the residual drift is dominated by two key coordinate points which are $(2,0)$ and $\left(0, D_{\max }\right)$. Point $(2,0)$ indicates that the residual drift is equal to zero if the SC factor reaches 2; point $\left(0, D_{\max }\right)$ indicates that the residual drift is equal to the maximum drift if the SC factor is 0 . The upper limit of residual drift $D_{\text {upres }}$ at different drifts can be expressed as Eq. (14). Wang et al. (2019) proposed a formula for the RSC UHPC bridge 
column with a hollow section to calculate the upper limit of residual drift, as shown in 454 Eq. (15). Eq. (14) is very similar to Eq. (15), the only difference is that Eq. (15) believes the residual drift is equal zero when the SC factor is 2.5. Therefore, Eq. (15) is more conservative as shown in Fig. 11. However, it does not mean that the concrete material or the section shape have great influence on the upper limit of residual drift. In (Wang et al. 2019), the SC factor defined as the moment contribution ratio is obtained by theoretical calculation, while the residual drift is obtained from the numerical results, exceeds 1.0, the residual drift increases in a smooth way. Meanwhile, the distribution of

$$
\text { there are some special points the SC factors of which exceed 1, while the corresponding }
$$
residual drift is very small and approximate to zero. These special points show an entirely different pattern of distribution. In order to explain the phenomenon, the source of these special points is checked, finding most of them are obtained from the specimens PD1-PD6, PT1-PT6, and G1-G5. $P_{\mathrm{d}}, \rho_{\mathrm{PT}}$ and $\eta_{\mathrm{G}}$ all have great negative effect on the ED parameter, so the influence of the ED parameter on the residual drift distribution is studied as shown in Fig. 12. When the ED parameter exceeds 0.75 , the residual drift is very sensitive to it, especially within the range of 0.75 to 1.0 , the residual drift grows rapidly as the ED parameter increases; when the ED parameter residual drift is stratified because the residual drift depends heavily on the maximum 
drift. On the other hand, it can be concluded that the residual drift is close to zero when the ED parameter is less than 0.75 , which is not related to the maximum drift.

As shown in Fig.13, the data in Fig.11 are collected and the points of which the ED parameter is larger than 0.75 are removed. It can be found that the most of the special points are filtered out, and the filtered data exhibit a more obvious linear distribution characteristic. Regression analyses are performed for the filtered data, and the relation between the residual drift at a certain drift and the SC factor is established as follows:

$$
\begin{gathered}
D_{\text {res }, 2 \%}=-1.4 \lambda_{\text {sC }}+1.936 \\
D_{\text {res }, 3 \%}=-1.972 \lambda_{\mathrm{SC}}+2.974 \\
D_{\text {res }, 4 \%}=-2.515 \lambda_{\mathrm{sC}}+3.973 \\
D_{\text {res }, 5 \%}=-3 \lambda_{\text {SC }}+4.9
\end{gathered}
$$

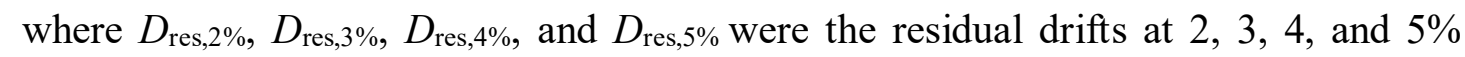
drift. It should be noted the set of formula can be used to estimate the residual drift under cyclic loading on the premise that the ED parameter exceeds 0.75 . If the parameter is smaller than 0.75 , the residual drift can be ignored. The correlation coefficients of Eq. (16a), Eq. (16b), Eq. (16c), Eq. (16d) are 86.6\%, 85.6\%, 85.4\% and $84.8 \%$, respectively.

Too large value of $L_{0}$ is an important reason leading to the discreteness of the formulas. As shown in Fig.13, there are lots of points descend faster as the SC factor increases, this is because too large value of $L_{0}$ will change the unloading path and aggravates the pinching effect, meanwhile, the $\mathrm{SC}$ factor is not sensitive to $L_{0}$. As a result, the residual drift is reduced at the cost of a slight reduction in strength and energy 
498

L5 are given as an example, as shown in Fig.14. In fact, a too long unbonded length will not be designed generally due to it may lead to the buckling of ED bars, so it is unnecessary to pay much attention on the effect of $L_{0}$.
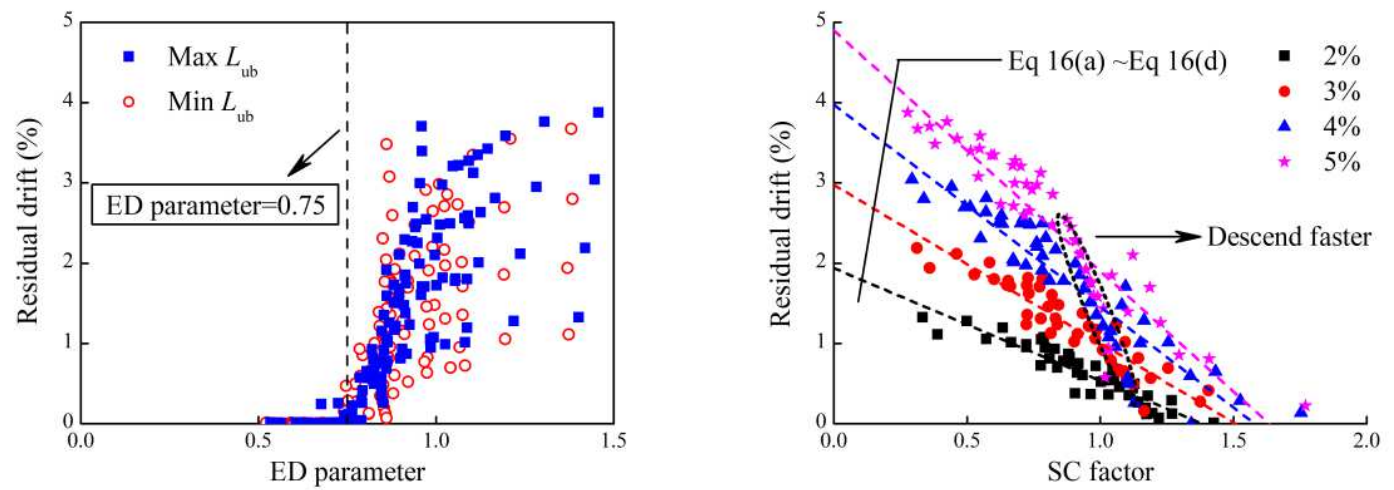

Fig. 12 Effect of ED parameter on residual drift distribution

Fig. 13 Regression analysis

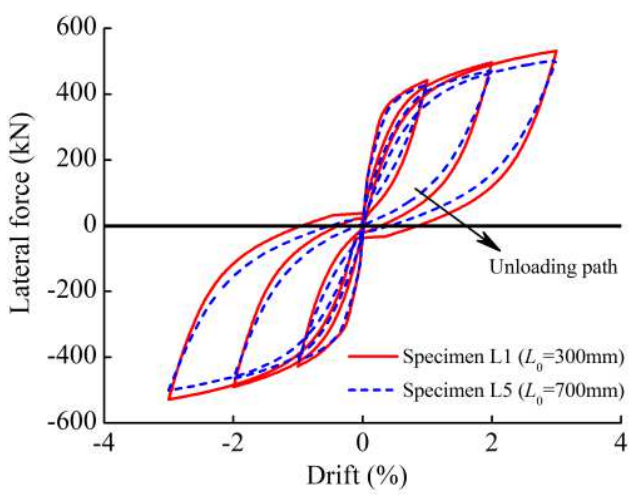

(a) Maximum $L_{\mathrm{ub}}$

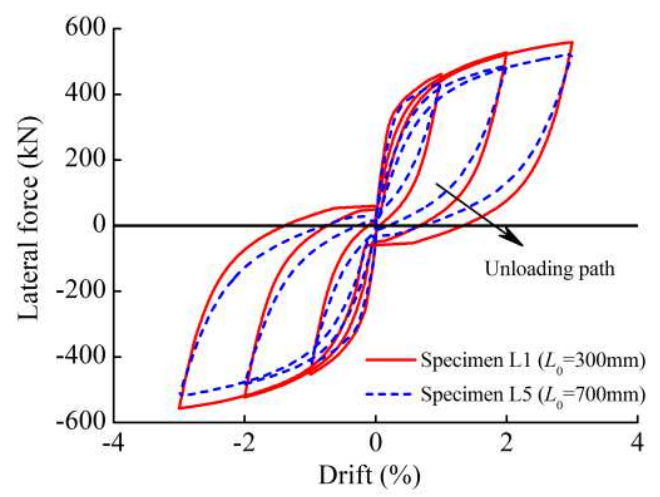

(b) Minimum $L_{\mathrm{ub}}$

Fig. 14 Comparison of hysteretic curves between specimen L1 and L5

Palermo et al. (2007) conducted a cyclic loading test on four RSC bridge pier specimens. There specimens were named PT1, HBD1, PT2 and HBD2, the only different between specimen PT1 (PT2) and HBD1 (HBD2) is the former lacks of ED bars. The SC factors and ED parameters of specimen HBD1 and HBD2 can be obtained from the test results. A comparison of the test results with the predictive residual drift is given as shown in Table 7. 
Table 7 Comparison of the test results with predictive results

\begin{tabular}{ccccccc}
\hline \multirow{2}{*}{ Specimens } & Drift & SC factor & ED parameter & \multicolumn{3}{c}{ Residual drift (\%) } \\
\cline { 5 - 7 } & & & & Test & Upper limit & Predictive result \\
\hline \multirow{2}{*}{ HBD1 } & $2 \%$ & 1 & 0.98 & 0.94 & 1 & 0.54 \\
& $3 \%$ & 0.98 & 0.97 & 1.55 & 1.53 & 1.04 \\
HBD2 & $2 \%$ & 1.4 & 0.83 & 0.23 & 0.6 & 0 \\
\hline
\end{tabular}

513

514

\section{Conclusion}

This paper uses numerical method to investigate and predict the residual displacement of RSC columns under cyclic loading. The SC factor and ED parameter are regarded as the important parameters to govern the residual displacement. The contribution of eight design parameters at different drifts is discussed by factorial analysis. The effect of the SC factor and ED parameter on the residual drift distribution is analyzed statistically. During the process, the uncertainty of $L_{\mathrm{ub}}$ in numerical model is considered. Finally, a set of predictive formulas is proposed by regression analyses.

Based on the analyses, the following conclusions can be drawn:

(1) Ignoring the strain penetration of ED bars will underestimate the self-centering capacity of RSC columns, and conservative residual displacement will be obtained.

(2) The total contribution of the eight parameters to the SC factor and ED parameter are stable and maintain at $84 \%$ and $95 \%$ around, respectively. No significant interaction between these factors is observed. Due to the P- $\Delta$ effect, the contribution of the gravity loading ratio to the $\mathrm{SC}$ factor will decreases rapidly as the drift increase, and the effect of the aspect ratio will grow.

(3) The SC factor, ED parameter, and maximum drift dominate the distribution of residual drift under cyclic loading. When the SC factor exceeds 2.0 or the ED parameter is smaller than 0.75 , the residual drift can be neglected. In other situations, the residual 
532

drift can be estimated using the upper limit formula and the regression formula.

(4) The unbonded length of ED bars has little influence on the SC factor and the ED parameter. However, if the unbonded length is too long, the residual displacement can be diminished effectively because of the changed unloading path.

\section{Declarations}

Funding This work is supported by National Natural Science Foundation of China (Grant No. 51908265 and No. 52008186) and Fund for Excellent Young Scholars of LUT (Grant No. 04-061810).

Conflict of interest The authors declare that they have no known competing financial interests or personal relationships that could have appeared to influence the work reported in this paper.

Availability of data and material Not applicable.

Code availability Not applicable.

Authors' contributions Yan Shi and Zhengwu Zhong contributed to the modelling and the analysis of the numerical results. The first draft of the manuscript was written by Zhengwu Zhong, with the contribution of Zhichao Zhang for the editing of the figures and tables. Yan Shi, Jianping Han and Hu Cheng participated in the review of the document and read and approved the final manuscript.

\section{Reference}

[1] Han Q, Du X, Liu J, et al. Seismic damage of highway bridges during the 2008 Wenchuan earthquake[J]. Earthquake Engineering \& Engineering Vibration 2009;8(2):263-73.

[2] Shi Y, Zhong Z, Qin H, et al. Toggle buckling-restrained brace systems and a corresponding design method for the seismic retrofit of bridge bents[J]. Engineering Structures, 2020, $221: 110996$.

[3] Kawashima K, Macrae G A, Hoshikuma J I, et al. Residual drift response spectrum[J]. Journal of Structural Engineering, 1998, 124(5):523-530

[4] Uma SR, Pampanin S, Christopoulos C. Development of probabilistic framework for 
performance-based seismic assessment of structures considering residual deformations $[\mathrm{J}]$. Journal of Earthquake Engineering, 2010,14(7):1092-1111.

[5] Palermo A, Mashal M. Accelerated bridge construction (ABC) and seismic damage resistant technology: A New Zealand challenge[J]. Bulletin of the New Zealand Society for Earthquake Engineering, 2012, 45(3): 123-134.

[6] Marsh M L, Wernli M, Garrett B E, et al. Application of accelerated bridge construction connections in moderate-to-high seismic regions, NCHRP Report 698[R]. Transportation 
with both steel and CFRP bars[J]. Composite Structures, 2017, 178: 195-209.

590

591

592

[16] Roh H, Reinhorn A M. Hysteretic behavior of precast segmental bridge piers with superelastic shape memory alloy bars[J]. Engineering Structures, 2010, 32(10): 3394-3403.

[17] Japan Road Association. specifications for highway bridges-Part V Seismic design[M]. Tokyo: Marusan Publishing, 2002.

[18] Liossatou E, Fardis M N. Near-fault effects on residual drifts of RC structures[J]. Earthquake Engineering \& Structural Dynamics, 2016, 45(9):1391-1409.

[19] Cheng H, Li H, Wang D, et al. Research on the influencing factors for residual drifts of RC bridge columns subjected to earthquake loading[J]. Bulletin of Earthquake Engineering, 2016, 14(8):2229-2257.

[20] Liossatou E, Fardis M N. Residual drifts of RC structures as SDOF systems[J]. Earthquake Engineering \& Structural Dynamics, 2015, 44(5):713-734.

[21] Ji D, Wen W, Zhai C, et al. Residual drift ratios of SDOF systems subjected to ground motions recorded on soft soils[J]. Soil Dynamics \& Earthquake Engineering, 2018, 115:331-335.

[22] Amiri S, Bojorquez E. Residual drift ratios of structures under mainshock-aftershock sequences[J]. Soil Dynamics \& Earthquake Engineering, 2019, 121:179-193.

[23] Zhan S, Jian Z. Dimensional estimation of residual-drift demands for bilinear bridges under near-fault ground motions[J]. Journal of Bridge Engineering, 2018, 23(11):04018087.

[24] Quinde P, Teran A, Reinoso E. Residual drift estimation for soft soils: Application to Mexico city lake-bed[J]. Soil Dynamics \& Earthquake Engineering, 2019, 130:105970.

[25] Li S, Zhao T, Alam MS, et al. Probabilistic seismic vulnerability and loss assessment of a seismic resistance bridge system with post-tensioning precast segmental ultra-high performance concrete bridge columns[J]. Engineering Structures, 2020, 225: 111321.

[26] Ou Y C, Chiewanichakorn M, Aref A J, et al. Seismic performance of segmental precast unbonded posttensioned concrete bridge columns[J]. Journal of Structural Engineering, 2007, 133(11):1636-1647.

[27] Cai Z, Zhou Z, Wang Z. Influencing factors of residual drifts of precast segmental bridge columns with energy dissipation bars[J]. Advances in Structural Engineering, 2019, 22(1):126-140.

[28] Liu X, Li J, Tsang H H, et al. Evaluating self-centering behavior of unbonded prestressed bridge 
columns using a new performance index based on quasi-static analysis[J]. Journal of Earthquake \& Tsunami, 2018, 12:1850001.

[29] Wang Z, Wang J, Zhao G, et al. Design criterion for the self-centering capacity of precast segmental UHPC bridge columns with unbonded post-tensioning tendons[J]. Engineering Structures, 2019, 200: 109706.

[30] Ahmdi E, Kashani M M. Numerical investigation of nonlinear static and dynamic behaviour of self-centring rocking segmental bridge piers[J]. Soil Dynamics \& Earthquake Engineering, 2020, 128: 105876.

[31] Marriott D, Pampanin S, Palermo A. Quasi-static and pseudo-dynamic testing of unbonded post-tensioned rocking bridge piers with external replaceable dissipaters[J]. Earthquake Engineering \& Structural Dynamics, 2009, 38(3): 331-354.

[32] Priestley M J N, Calvi G M, Kowalsky M J. Displacement-based seismic design of structures[M]. Pavia: IUSS Press, 2007.

[33] Kowalsky M J, Priestley M J N, Macrae G A. Displacement-based design of RC bridge columns in seismic regions[J]. Earthquake Engineering \& Structural Dynamics, 1995, 24(12): 1623-1643.

[34] Mantawy I M, Sanders D H, Eberhard M O, et al. Modelling of debonded reinforcement in ABC connections designed for seismic zones[J]. Engineering Structures, 2019, 198: 109351.

[35] Pampanin S, Priestley M J N, Sritharan S. Analytical modelling of the seismic behaviour of precast concrete frames designed with ductile connections[J]. Journal of Earthquake Engineering, 2001, 5(03): 329-367.

[36] Bu Z Y, Ou Y C . Simplified Analytical Pushover Method for Precast Segmental Concrete Bridge Columns[J]. Advances in Structural Engineering, 2013, 16(5):805-822.

[37] Guo J, Xin K G, He M H, et al. Experimental study and analysis on the seismic performance of a self-centering bridge pier[J]. Engineering Mechanics, 2012(A01):29-34.

[38] Hieber, D.G, Wacker, J.M, et al. Precast concrete pier systems for rapid construction of bridges in seismic regions(No. WA-RD 611.1)[R]. University of Washington, Seattle, Washington, USA, 2005.

[39] Weng Y K, Pampanin S, Palermo A, et al. Self-centering structural systems with combination of hysteretic and viscous energy dissipations[J]. Earthquake Engineering \& Structural Dynamics, $2010,39(10)$. 
649 [40] Pampanin S, Priestley M J N, Sritharan S. Analytical modelling of the seismic behaviour of 650 precast concrete frames designed with ductile connections[J]. Journal of Earthquake Engineering, $651 \quad 2001,5(03): 329-367$.

652 [41] Montgomery D C. Design and analysis of experiments[M]. New York: John Wiley and Sons, 653 2008. 